\title{
On the Behavior of Coupled Shear Walls: Numerical Assessment of Reinforced Concrete Coupling Beam Parameters
}

\author{
Omar M. Nofal ${ }^{*}, 2$, Mostafa Elsayed ${ }^{2}$, Adel Akl ${ }^{2}$, Mohamed Abdel-Mooty ${ }^{3}$ \\ 1. Department of Civil and Environmental Engineering, Colorado State University, Fort Collins, Colorado, USA \\ 2. Structural Engineering Department, Faculty of Engineering, Cairo University, Gamaet El Qahera St., Giza, \\ Egypt \\ 3. Department of Construction Engineering, The American University in Cairo, Cairo, Egypt \\ E-mail: omar.nofal@colostate.edu
}

Received: 22 May 2021; Accepted: 8 July 2021; Available online: 15 August 2021

\begin{abstract}
Modern construction of high-rise and tall buildings depends on coupled shear walls system to resist the lateral loads induced by wind and earthquake hazards. The lateral behavior of this system depends on the structural behavior of its components including coupling beams and shear walls. Although many research studies in the literature investigated coupling beams and shear walls, these studies stopped short of investigating the coupled shear walls as a system. Therefore, in this research, the effect of the coupling beam parameters on the nonlinear behavior of the coupled shear walls system was investigated. The full behavior of a 10-story coupled shear wall system was modeled using a series of finite element analyses. The analysis comprised of testing several coupling beam parameters to capture the effect of each parameter on system response including load-deflection behavior, coupling ratio, crack pattern, and failure mechanism. The results indicated that a span-to-depth ratio equal to two is a turning point for the coupling beam behavior. Specifically, the behavior is dominated by ordinary flexure for a ratio of more than two and deep beam behavior for a ratio of less than two. This study showed that the coupling beam width does not have a significant effect on the coupled shear wall response. Additionally, it was concluded that the excessive coupling beam diagonal reinforcement could significantly affect the coupled shear walls behavior and therefore an upper limit for the diagonal reinforcement was provided. Moreover, limitations on the longitudinal and diagonal reinforcement and stirrups are presented herein. The analysis results presented in this paper can provide guidance for practitioners in terms of making decisions about the coupling ratio of the coupled shear walls.
\end{abstract}

Keywords: Seismic loads; Lateral loads; Pushover analysis; Nonlinear analysis; Finite element analysis; VecTor2.

\section{Introduction}

Coupled Shear Walls (CSWs) enable two walls, or more, to act as one wall with a certain level of efficiency, depending on how much coupling is provided by the Coupling Beam (CB) [1]. CBs are usually provided on each floor to connect the walls and efficiently control their behavior. These beams limit the axial deformation in each wall in terms of tension in one wall and compression in the other coupled wall. Such action induces an internal couple thereby improving the overall behavior of the walls through better energy dissipation, less wall rotation, as well as a reduction in inter-story drift, peak roof drift, and base shear while ensuring a more evenly distributed heightwise deflection profile. Shear walls are used as a primary lateral load resisting system in high-rise buildings, but sometimes they are designed and constructed with two or several walls connected with a deep short beam to accommodate openings for windows or doors. This combination of walls and CBs is termed as a pier-spandrel system. Typically, walls connected at different levels with CBs act as a frame where the piers represent columns and the spandrels represent beams. Those spandrels are responsible for coupling the lateral load resistance of adjacent walls. Therefore, a Reinforced Concrete (RC) CB with a certain reinforcement (RFT) layout can be used as a mean of increasing the wall resistance and provide better energy dissipation.

In this context, the extent of coupling provided by a coupling beam is termed as the Coupling Ratio (CR) which could be calculated using Eq. (1) [2]. Figure 1 presents a schematic illustration of how the level of coupling affects the axial stresses on the wall cross-section. In the case of no coupling, the overturning moment will be resisted through the walls' flexure strength. If there is enough coupling between the walls, end moments will be induced and the accumulated shear in the CBs will contribute to resisting a portion of the total overturning moment. 


$$
C R=\frac{T L}{T L+\left(M_{1}+M_{2}\right)}=\frac{C L}{C L+\left(M_{1}+M_{2}\right)}
$$

where $\mathrm{T}$ is the total tension in one wall and $\mathrm{C}$ is the total compression in the other wall and the value of tension force is the same value of compression force due to symmetry as shown in Figure 1, which is equal the total accumulated shear in the CBs $\left(\sum \mathrm{V}_{\text {beams }}\right)$. $\mathrm{L}$ is the arm of the coupling force, which extends from the centroid of the wall piers. The total overturning moment is the sum of the moment in each wall beside the moment induced by the coupling action.

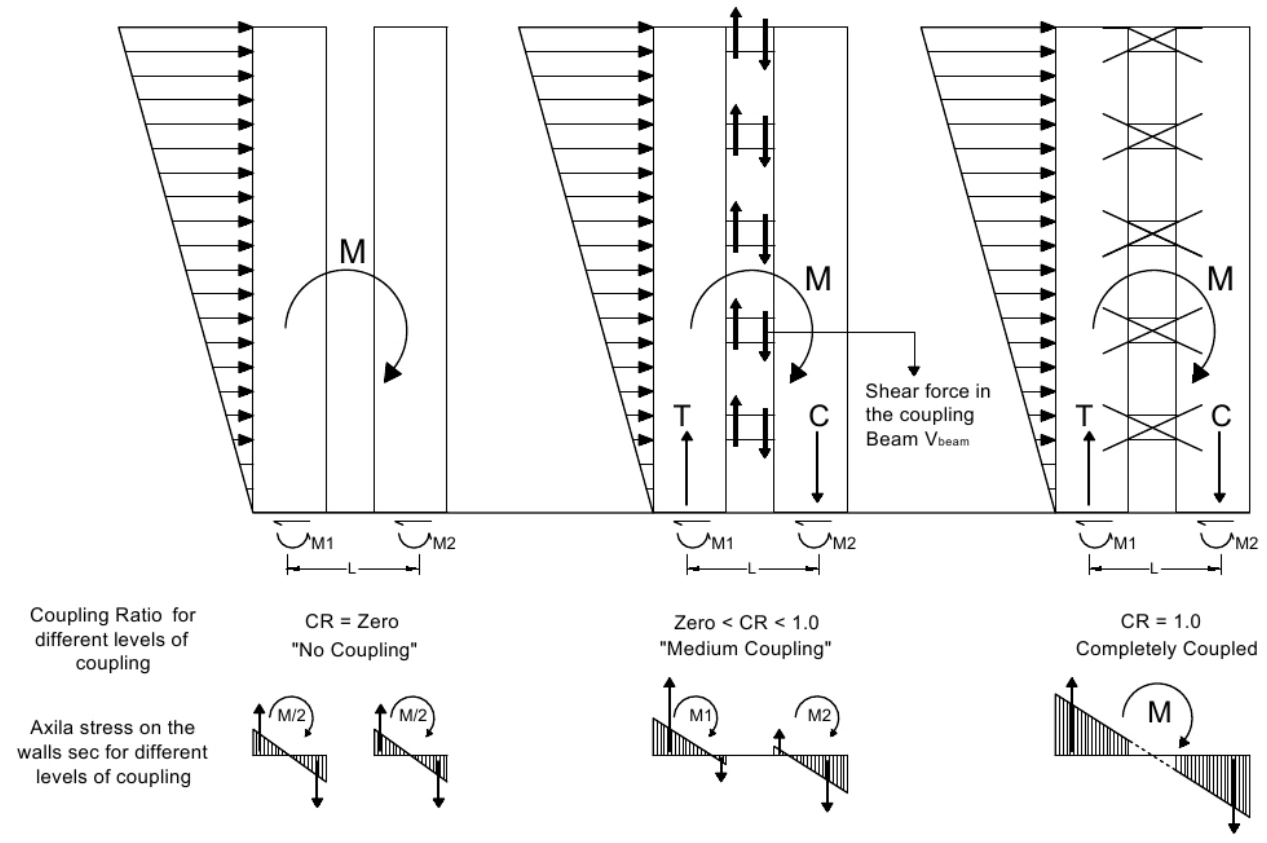

Figure 1. Schematic representation of the different levels of coupling and their accompanied wall state of stresses.

Many researchers over the past decades found that this system provides high lateral stiffness and strength to the structure, which makes it a preferable lateral load resisting system by most building designers [3-7]. Therefore, such systems are particularly well suited for regions of moderate-to-high seismic risk. Various extensive studies were conducted on RC CBs to differentiate their behavior from the ordinary flexure beam behavior. These studies included experimental tests [8-13] and numerical studies [14-17]. A number of researchers have investigated the CR in hybrid CSWs (HCSWs) (e.g. El-Tawil and Kuenzli [18], El-Tawil et al. [2], Wang et al. [19] and as well as RC CSWs (e.g. Harries and McNeice [20]). Their findings concluded that, over-coupling a certain system of HCSWs up to a $\mathrm{CR}=60 \%$ results in failure in the wall from cracking and crushing before the beams reach a certain ductility level. However, an upper limit of 66\% for the CR for HCSWs was proposed by Harries [16]. On the other hand, RC CSWs of a 10-story uniform wall with an RC CBs having a CR=74\% had been investigated by Harries et al. [7]. This system exhibited good behavior and satisfied all articulated performance criteria. A 30-story RC structure with CR ranges between $67 \%$ and $78 \%$ was investigated by Harries and McNeice [20] to evaluate the current strength-based design method which ended with exceptional high coupling beam shear demands that exceeded the prescribed code limits due to the used high coupling ratio which in turn resulted in large wall overstrength factor. El-Tawil and Kuenzli [18] tested several CBs to investigate the effect of the CR on the inelastic response of the CSWs. It was concluded that, if the $\mathrm{CR}=0 \%$ (uncoupled), the system will show very poor behavior from the point of ductility (deflection, wall rotation, and drift) in addition to crushing failure at the lower part of walls (plastic hinge region). On the other hand, the Hybrid Coupled Shear Wall (HCSW) systems with CRs 30$40 \%$ have been shown to provide optimal performance for the economy because it requires less concrete and steel materials and its behavior is better than other lateral load resisting systems [21].

Several experimental studies investigated the coupled shear wall system in terms of the reinforcement layout for the coupling beams $[8,22,23]$. In terms of the numerical modeling of CBs, a number of studies over the previous decades have been conducted with CB's modeled as an equivalent continuous shear medium (e.g. Glück [24], Paulay [25], Pekau and Gocevski [26]) and strut-and-tie model [27]. Other researchers used linear elasto-plastic analysis based on the wide column frame analogy (e.g. Kwan and Zhao [28], Kwan [29], Nayar and Coull [30], Ping and Sheliang [31]). Discrete lumped mass plasticity models have also been used to model the CB's as an element with a concentrated shear or flexure stiffness spring according to the predominated behavior in the regions 
under consideration and arms to simulate the rigid portions (e.g. Harries et al. [32], Pala and Özmen [33]). All these studies have provided significant contributions in modeling the nonlinear behavior of CB's because of their unique behavior compared to ordinary beams.

For an accurate assessment of the behavior of CBs and their modes of failure (shear or flexure), modeling CB as a discrete frame element should be avoided. This is because using discrete frame elements will not allow capturing beam-wall interaction including the effect of reinforcement (RFT) layout which has a substantial effect on the predicted behavior. The interaction zone between the CB and walls is critical and must be accurately modeled to capture the stress concentration at the beam-wall joint since it will impact the overall behavior of the CSWs [34]. The beam-wall joint must also include modeling of the wall panel near the CB for better accuracy. RFT Modeling was ranged from modeling it as discrete reinforcing bars [35,36] to a smeared representation [14]. However, for better bond-slip behavior representation, steel bars can be modeled as discrete reinforcing bars. Such representation allows for the dowel action to be incorporated in the model, which is an important component of shear transfer in the cracked concrete [36]. Finally, confinement should also be included in the concrete model by adjusting the stress-strain relationship, which has been shown to have a substantial influence on the overall behavior of the wall [37]. Analytical models of the reinforced concrete coupled shear walls and coupling beams were developed using beam-shell model [38] A number of nonlinear finite element analyses of reinforced concrete CSWs were conducted using discrete crack models but recently the smeared crack model has become the predominant approach after including the dowel action in the smeared crack representation [15] and the bond-slip action [39].

While all these studies provided valuable insight into the behavior of CBs as an element and showed how the CB parameters will affect CBs behavior, they have stopped short of investigating the effect of the CB parameters as an element on the response of the CSWs as a system. Therefore, this study did not only focus on CBs behavior but also included the impact of CBs parameters as an element on the CSWs behavior as a system. The main objective of this study is to provide detailed quantification of the amount of coupling exhibited by the coupled shear walls under different CBs parameters. This was done by conducting a detailed investigation of the parameters that have a dominant effect on the extent of coupling including the CB depth, width, diagonal RFT, longitudinal RFT, and stirrups. Recommended values of these parameters were provided to achieve an optimal CSWs behavior in terms of load-deflection behavior, coupling ratio, crack pattern, and failure mechanism.

\section{Material and load models verification}

A finite element model for the CB was developed using VecTor2 [40]. VecTor2 is a state-of-the-art nonlinear finite element analysis of two-dimensional reinforced concrete membrane structures subjected to quasi-static load conditions. VecTor2 is based on the Disturbed Stress Field Model (DSFM) [41] and the Modified Compression Field Theory (MCFT) [42]. The use of the Modified Compression Field Theory enabled models to accurately capture cracking, compression-softening, tension-stiffening, the confining of the reinforcing bars, dowel action, and the crack slip action. In this study, VecTor2 was utilized to numerically model previous experimental tests of CBs to verify the materials' models that will be used in this study. These experimental tests were done by Galano and Vignoli [8] to quantify the significance of the CB's RFT configurations and to what extent these different configurations could affect the CB behavior. Galano and Vignoli [8] tested four different RFT configurations for the coupling beams, however, one RFT configuration of diagonally reinforced specimen P05(b1) was selected for this verification. P05(b1) consists of two loading blocks $930 \mathrm{~mm}$ (height) x $1100 \mathrm{~mm}$ (length) x $150 \mathrm{~mm}$ (width) and a CB $400 \mathrm{~mm}$ (height) x $600 \mathrm{~mm}$ (length) x $150 \mathrm{~mm}$ (width) as shown in Figure 2. The span-depth ratio is 1.5 and the main RFT is $10 \mathrm{~mm}$ diagonal 4 bars with $6 \mathrm{~mm}$ horizontal bars and 5 bars of $6 \mathrm{~mm}$ diameter were used. The reported average value of the steel yield strength was $f_{\text {sy }}=567 \mathrm{MPa}$ and the ultimate strength was $\mathrm{f}_{\mathrm{st}}=660$ $\mathrm{MPa}$, and the steel modulus of elasticity was found to be $\mathrm{E}_{\mathrm{s}}=206 \times 10^{3} \mathrm{MPa}$. The concrete had a $10 \mathrm{~mm}$ maximum aggregate size with complete grain size distribution and the average modulus of elasticity was $\mathrm{E}_{\mathrm{c}}=24,400 \mathrm{MPa}$. The specimen used for material and load model validation has longitudinal and transversal RFT ratios of 0.524 and 0.39 , respectively. The used concrete density was $20.76 \mathrm{kN} / \mathrm{m}^{3}$, and the mean cylinder compressive was 39.9 MPa.

There are wide varieties of concrete and steel materials and constitutive models incorporated in VecTor2. These constitutive models and materials were verified in a number of researches (e.g. Constantin [43], R. Hoult et al. [44]). The chosen constitutive models for this research are tabulated in Table 1 with proper references for each model and the readers are referred to VecTor2 User's Manual [40] for more details about these models and the applicability of each one.

Figure 3 ( $\mathrm{a}$ and $\mathrm{b}$ ) show the boundary conditions and deformed shape adopted for the numerical model. The vertical loads due to the self-weight of the specimen were calculated and assigned as a prescribed load lumped at the joints, which is constant at each load step. On the other hand, the vertical shear load on the right block was assigned as a displacement-controlled load starting from zero and incrementally increase one mm 
upward/downward until the model becomes numerically unstable and fails. Two different finite element models (i and ii) for specimen P05 (b1) were developed as shown in Figure 4. For the first analytical model (i), the 4 diagonal bars were lumped into one discrete truss bar element as shown in Figure 4 (i). For the second analytical model (ii), the 4 diagonal bars were modeled by taking into consideration their elevation and in-plane distance as shown in Figure 4 (ii).

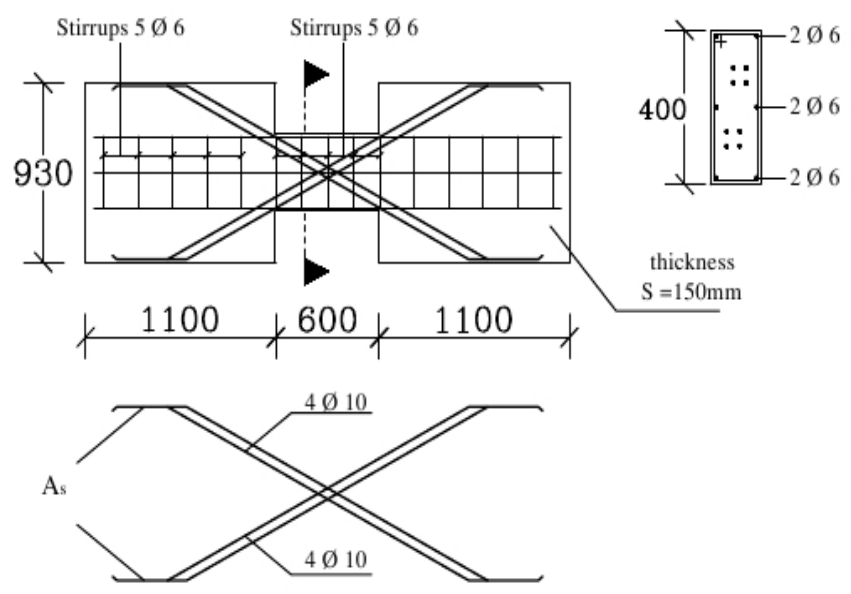

Figure 2. Details and dimensions (mm) of specimen P05(b1)

Table 1. Material Models assignment for VecTor2

\begin{tabular}{ll}
\hline Constitutive Behavior & Model \\
\hline Compression Pre-Peak & Parabola [45] \\
Compression Post-Peak & Modified Park-Kent [46,47] \\
Compression Softening & Vecchio 1992-A (e1/e2-Form) [40] \\
Tension Stiffening & Modified Benz 2003[48] \\
Tension Softening & Linear \\
Tension Splitting & Not Considered \\
Confinement Strength & Kupfer / Richart Model [49-51] \\
Concrete Dilation & Variable-Kupfer \\
Cracking Criterion & Mohr-Coulomb (Stress) \\
Crack Stress Calc. & Basic (DSFT/MCFT) \\
Crack Width Check & Agg/2.5 Max Crack Width \\
Crack Slip Calc. & Walraven (Monotonic) [42] \\
Concrete Hysteresis & Non-Linear w/ Plastic Offsets \\
Steel Hysteresis & Elastic-Plastic w/ Hardening \\
Rebar Dowel Action & Tassios (Crack Slip) [52] \\
\hline
\end{tabular}

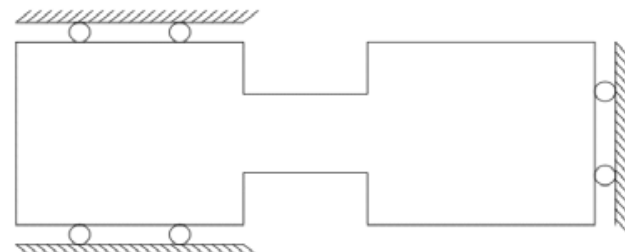

(a) Original

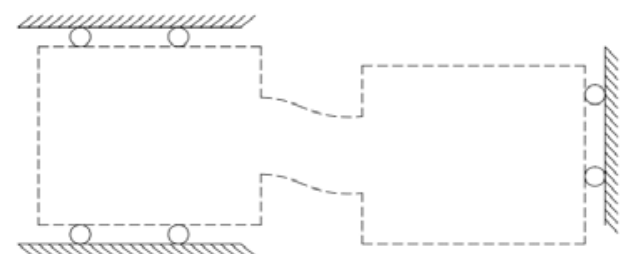

(b) Deformed

Figure 3. The CB boundary conditions.

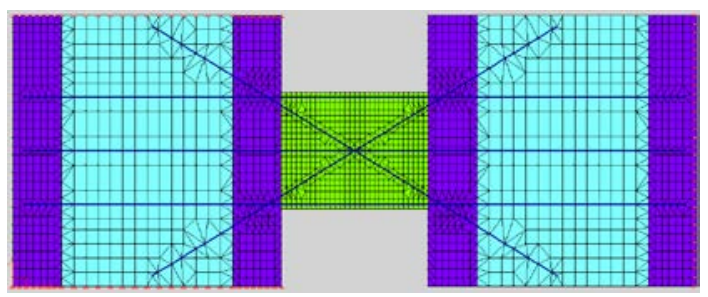

(i)

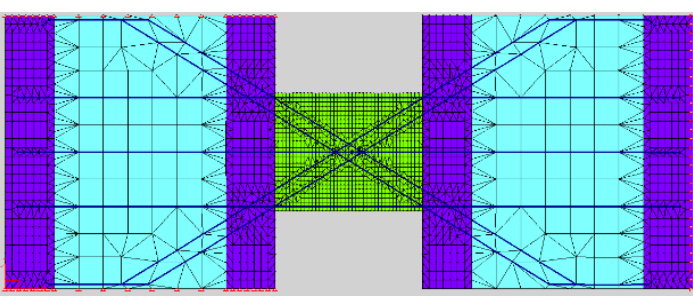

(ii)

Figure 4. The CB models type P05 (b1) in VecTor2. 


\subsection{Load-deflection behavior}

For the pre-peak stage, the two analytical models of P05 showed an excellent match between the analytical and experimental load-deflection curve before reaching the yielding load as shown in Fig. 5. However, analytical models showed a slightly higher-yielding load than the experimental results. For post-peak response, the analytical models underestimated the ultimate displacement of the specimens, but model (ii) showed a bit more ductile mode of failure with a delayed collapse and a better match with the experimental results in the post-peak response. The exact values of loads and deformations for experimental and analytical models at the yield and ultimate load are tabulated in Table 2.

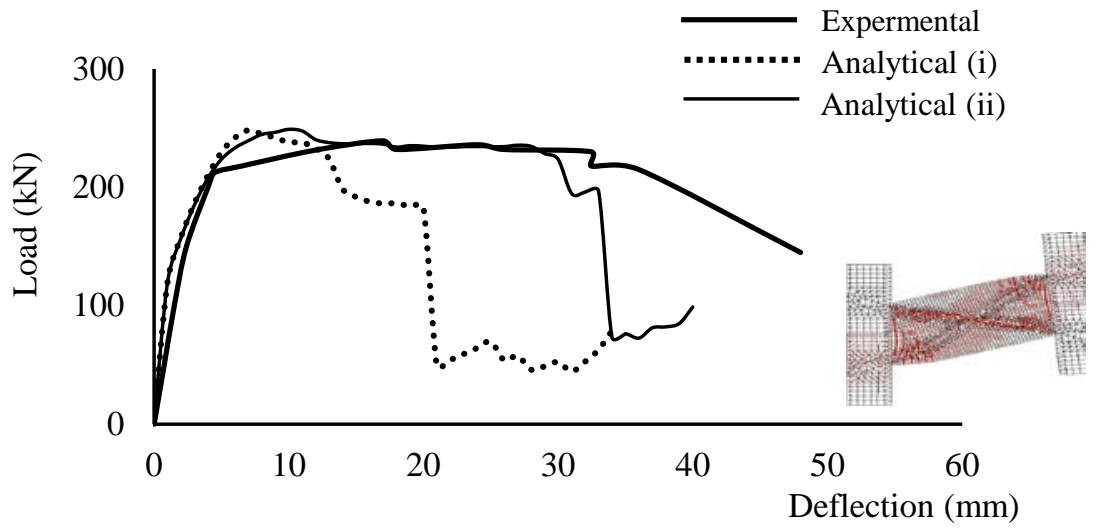

Figure 5. The analytical and experimental load-deflection curves of the Galano and Vignoli P05(b)

Table 2. Experimental and analytical load-deflection relationship at yield and ultimate loads.

\begin{tabular}{cccccccccc}
\hline & & \multicolumn{3}{c}{ Experimental } & \multicolumn{3}{c}{ Analytical } \\
\cline { 3 - 10 } Specimen & Type & \multicolumn{2}{c}{ Yield } & \multicolumn{2}{c}{ Ultimate } & \multicolumn{2}{c}{ Yield } & \multicolumn{2}{c}{ Ultimate } \\
\cline { 3 - 11 } & & $\begin{array}{c}\text { Load } \\
(\mathrm{kN})\end{array}$ & $\begin{array}{c}\text { Def. } \\
(\mathrm{mm})\end{array}$ & $\begin{array}{c}\text { Load } \\
(\mathrm{kN})\end{array}$ & $\begin{array}{c}\text { Def. } \\
(\mathrm{mm})\end{array}$ & $\begin{array}{c}\text { Load } \\
(\mathrm{kN})\end{array}$ & $\begin{array}{c}\text { Def. } \\
(\mathrm{mm})\end{array}$ & $\begin{array}{c}\text { Load } \\
(\mathrm{kN})\end{array}$ & $\begin{array}{c}\text { Def. } \\
(\mathrm{mm})\end{array}$ \\
\hline P05 (i) & b1 & 212 & 5.0 & 239 & 17.0 & 219 & 4.5 & 248 & 7.0 \\
P05 (ii) & b1 & 212 & 5.0 & 239 & 17.0 & 216 & 4.7 & 249 & 10.0 \\
\hline
\end{tabular}

The accuracy of the analytical model is deemed acceptable. The results from VecTor2 provide a good prediction of the model response from the yield point up to the ultimate load. However, the ultimate displacement is underpredicted and the published experimental results showed a more ductile mode of failure than the analytical models. Table 3 summarizes the response of the two tested numerical models with respect to the published experimental results which confirmed the accuracy of the chosen material and constitutive modes of concrete and steel using VecTor2.

Table 3. Experimental vs. analytical results in terms of load and deformation ratios.

\begin{tabular}{cccccc}
\hline Specimen & Type & $\mathrm{V}_{\mathrm{y}} / \mathrm{V}_{\text {ye }}$ & $\Delta_{\mathrm{y}} / \Delta_{\text {ye }}$ & $\mathrm{V}_{\mathrm{u}} / \mathrm{V}_{\text {ue }}$ & $\Delta_{\mathrm{u}} / \Delta_{\text {ue }}$ \\
\hline P05(i) & b1 & 1.03 & 0.9 & 1.036 & 0.41 \\
P05(ii) & b1 & 1.02 & 0.94 & 1.04 & 0.59 \\
\hline
\end{tabular}

Both models P05(i) and P05(ii) deliver almost the same level of results accuracy in the pre-peak stage in terms of yield shear stresses and deflections. However, P05(ii) shows a little better post-peak response than P05(i). Yet, model P05(ii) is more computationally intensive than model P05(i) with more mesh refining in between the two bars which will consume more elements from the reserved 6000 allowable elements within VecTor2 program capability. Therefore, if it comes to a bigger scale model of 10-story coupled shear walls, there will be much more need for better allocation of the reserved 6000 elements to be perfectly allocated for developing the whole 10-story model.

\subsection{Crack pattern and failure mechanism}

For VecTor2, the theoretical cracks appeared as red thick lines within the elements. The length and thickness of lines represent the tensile strain normal to the crack, which will control the crack width. The analytical crack pattern at the ultimate load stage for the two models of specimen P05 is shown in Fig. 6. Both experimental and 
analytical models showed that the dominant crack pattern is flexural cracks. These cracks will reduce the shear capacity of the concrete section at the beam-wall joint interface with more than $50 \%$ of the total beam shear capacity. Thereby, increasing the failure probability of the CB in the shear-sliding failure mode if shear RFT is not sufficient to prevent this action. According to Galano and Vignoli [8], the experiment showed that the flexure failure mode for P05 specimen will dominate. After shear cracks begin to open, two main vertical cracks form at the tension side exactly at the beam-wall joint, where the maximum bending moment is present. Such behavior allowed the CB high rotation after yielding without significant losses in strength. By the end of the load history, the width of the vertical crack became larger and the compression strut became unstable resulting in failure due to shear tension splitting as shown in Figure 6.

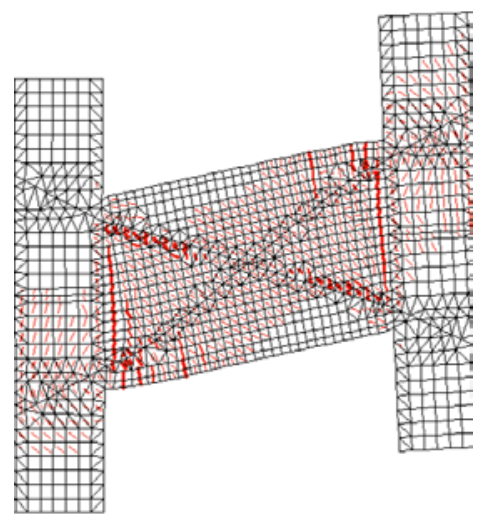

Analytical (i)

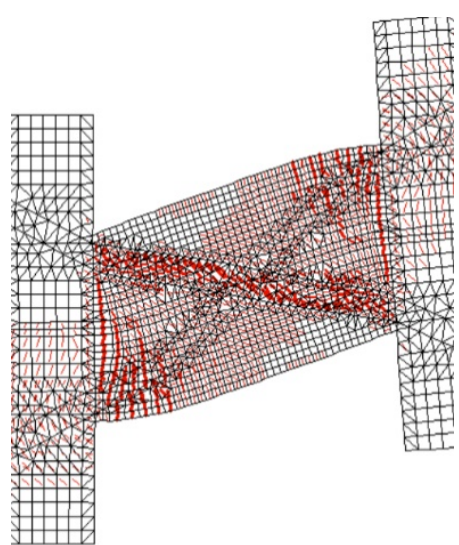

Analytical (ii)

Figure 6. The analytical crack pattern of specimen P05

\section{Methodology}

In order to work with realistic dimensions of a CSWs, a prototype of a $30 \mathrm{~m}$ 10-story commercial building was analyzed and designed with a main lateral load resisting system consisting of four $6.0 \mathrm{~m}$ shear walls in the $\mathrm{X}$ direction and a group of $3.0 \mathrm{~m}$ CSWs in the Y-direction using $1.8 \mathrm{~m} \mathrm{CB}$ as shown in Fig. 7. The wall thickness is $30.0 \mathrm{~cm}$. These dimensions were selected to accommodate the expected lateral loads for the building. A $25.0 \mathrm{~cm}$ thick flat slab with marginal beams on the perimeter was selected for the gravity system. Interior and exterior columns dimensions were assumed and there were two symmetrical voids to accommodate the stairwell and elevator shaft.

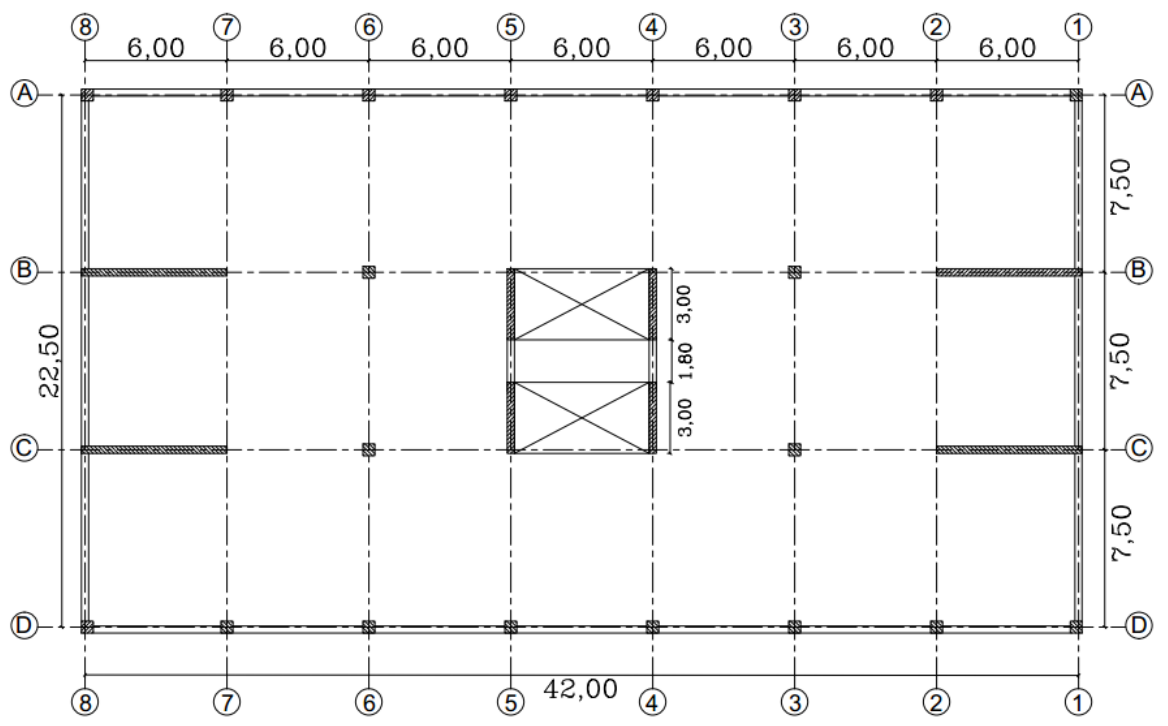

Figure. 7. A plan shows full dimensions of the chosen prototype. 


\subsection{Design of the CSWs elements}

Lateral load analysis was performed using ETABS 2016 to obtain design forces on the coupled wall system elements using the equivalent lateral forces procedures. Details of the analysis are available in Nofal et al. (2017). Modeling the CB as a spandrel in ETABS 2016 made it easy to extract the design forces as if it was a frame element. The results on the shear walls and CB are tabulated in Table 4. The design forces were then used to design both the shear wall and CB.

For the wall, two sections were designed according to the ACI 318-14 code [54] using spWall software [55]. One section in the plastic hinge region extends from the wall base up to $3.0 \mathrm{~m}$ above the base. The plastic hinge section is represented by the hatched area in Fig. 8(a) which was designed to resist a certain probable shear and moment which was set equal to 1.25 of the value of the design forces because this region is expected to form a plastic hinge with excessive cracking. The other section represents the rest of the wall and was designed for the calculated design forces without any scaling. Full details of the coupling beam and the wall profile and crosssection are shown in Fig. 8.

Table 4. Straining actions in the CSW system.

\begin{tabular}{lccc}
\hline Section Cut & $\mathrm{N}_{\mathrm{u}}(\mathrm{kN})$ & $\mathrm{Q}_{\mathrm{u}}(\mathrm{kN})$ & $\mathrm{M}_{\mathrm{u}}(\mathrm{kN} . \mathrm{m})$ \\
\hline Wall (Single Wall) & 1116 & 11272 & 3228 \\
CB (Max Internal Forces) & -- & 833 & 355 \\
\hline
\end{tabular}

* $\mathrm{N}_{\mathrm{u}}$ for the axial load, $\mathrm{Q}_{\mathrm{u}}$ for the shear load, and $\mathrm{M}_{\mathrm{u}}$ for bending moment

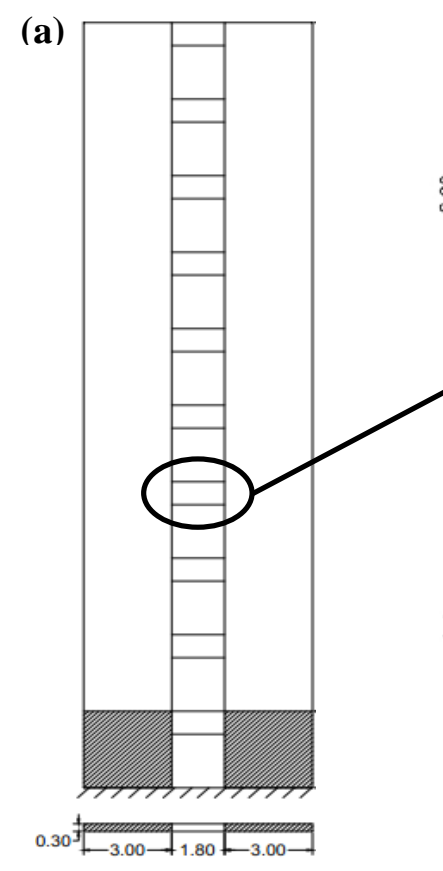

(b)
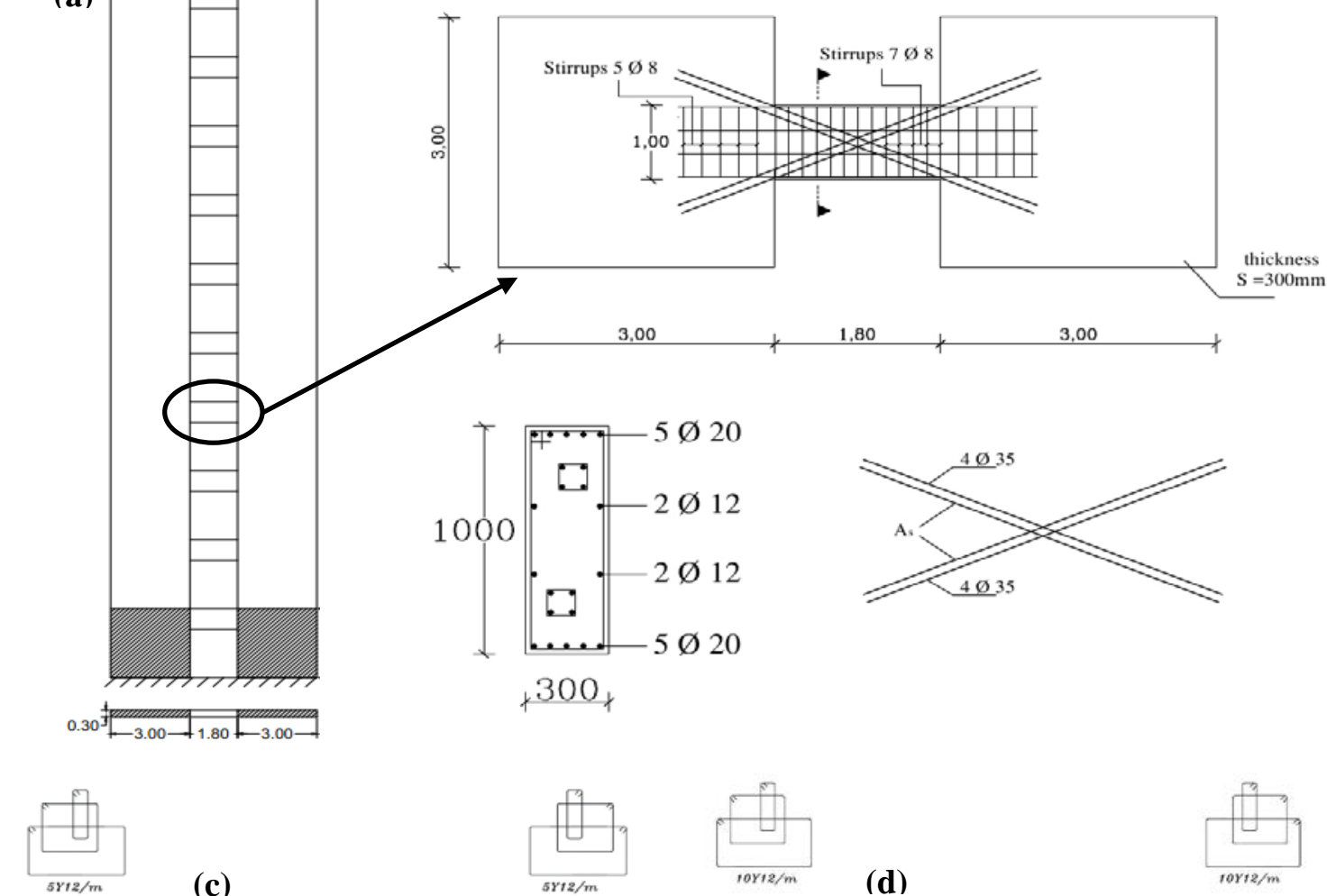

(c)
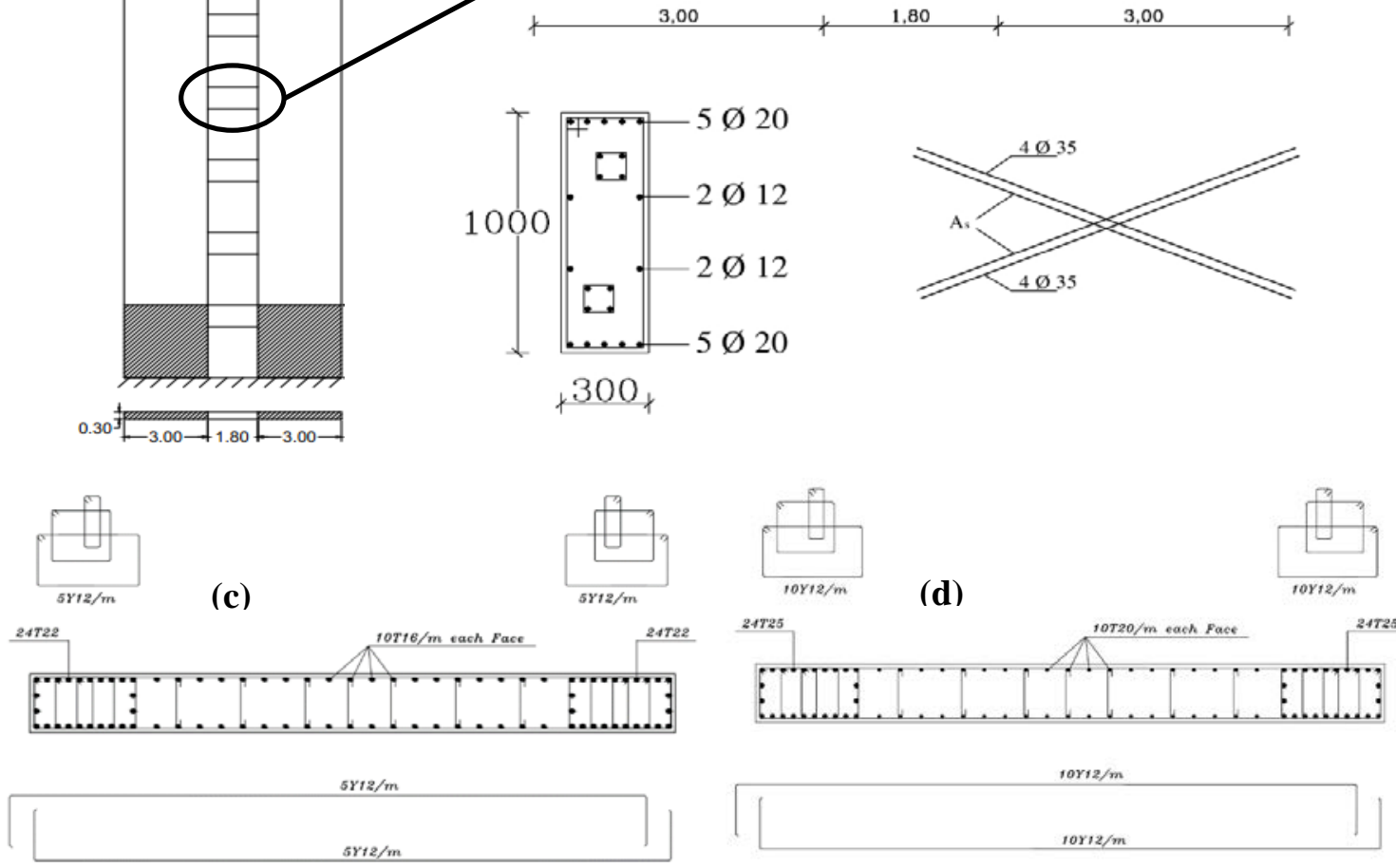

Figure 8. A complete profile and sections for the CB and CSWs: (a) CSWs profile; (b) CB profile and section; (c) Section in one wall outside plastic hinge region; (c) Section in one wall inside

\subsection{Parametric study using nonlinear static pushover analysis}

In this research, a parametric study was conducted on five important parameters of the coupling beam (depth, width, diagonal RFT, top and bottom RFT, and RFT shear stirrups). The base coupling beam parameters are 1000 
mm depth, 250 mm width, 4T25 diagonal RFT, 3T16 top and bottom RFT, and 8Y8 shear stirrups RFT. For each parameter, it will be changed according to Table 5 and the other four parameters will remain the same as the base coupling beam parameters which are in red in Table 5. Therefore, 25 CSWs models were developed to accomplish the parametric study.

Table 5. The parametric study models’ parameters

\begin{tabular}{ccccc}
\hline Depth $(\mathrm{mm})$ & Width $(\mathrm{mm})$ & Diagonal RFT & Top and Bottom RFT & Shear Stirrups RFT \\
\hline 800 & 150 & $4 \mathrm{~T} 20 \dagger$ & $3 \mathrm{~T} 10$ & $48^{*}$ \\
900 & 200 & $4 \mathrm{~T} 22$ & $3 \mathrm{~T} 12$ & $6 \mathrm{Y} 8$ \\
1000 & 250 & $4 \mathrm{~T} 25$ & $3 \mathrm{~T} 16$ & $8 \mathrm{Y} 8$ \\
1100 & 300 & $4 \mathrm{~T} 30$ & $3 \mathrm{~T} 20$ & $10 \mathrm{Y} 8$ \\
1200 & 350 & $4 \mathrm{~T} 35$ & $3 \mathrm{~T} 25$ & $12 \mathrm{Y} 8$ \\
\hline
\end{tabular}

$\dagger$ Four bars of $20 \mathrm{~mm}$ diameter rebar and $\mathrm{T}$ means $\mathrm{Fy} / \mathrm{Fu}=400 / 600 \mathrm{MPa}$

*Four bars of 8 mm diameter rebar and Y means Fy/Fu=280/360 MPa

The CSWs model had been developed using finite element analysis using VecTor2. The maximum allowable number of elements within VecTor2 is 6000 elements. Different mesh sizes were utilized to accommodate a 10story model without losing accuracy. Since CB is a major element of this study and the beam-wall interaction zone is very critical, so more fine mesh was used to enable capturing the accumulated stresses in this zone. Therefore, a small mesh size of $20 \mathrm{~cm}$ triangular element was utilized in the coupling beam zone and the wall boundary elements at the beam-wall interaction zone. A bigger mesh size of $25 \mathrm{~cm}$ was used at the free wall boundary elements and a coarser mesh of $50 \mathrm{~cm}$ was used in the mid part of the wall. For RFT modeling, there were two types of RFT had been used in the modeling of the shear wall. The first type is the smeared RFT which was used to model the distributed RFT and it has three values with three different colors in Fig. 9 depending on RFT setting angle and its ratio. The second type was the discrete RFT, which was used for the main lumped RFT (diagonal, top, and bottom RFT) of CBs. Table 6 shows the five different concrete material models which appear in different colors distinguishing different smeared RFT values within each material model. The first story of the coupled shear walls was reinforced with plastic hinge RFT which is bigger than the RFT in the rest of the wall.

Concrete and steel materials and constitutive models are the same ones used for the verification in Table 2. Gravity loads were calculated and then assigned as lumped forces on the joints. Then, the CSWs model was analyzed under lateral force using nonlinear static pushover analysis to quantify the resulted non-linear behavior of this system. To do so, a displacement-controlled load pattern was utilized for the pushover analysis using an inverted triangle displacement starting from zero displacement at the base and $10 \mathrm{~mm}$ displacement at the roof. This displacement is monotonically increased by one $\mathrm{mm}$ in each time step until the system failure. The pushover displacement profile is shown in Fig. 9.

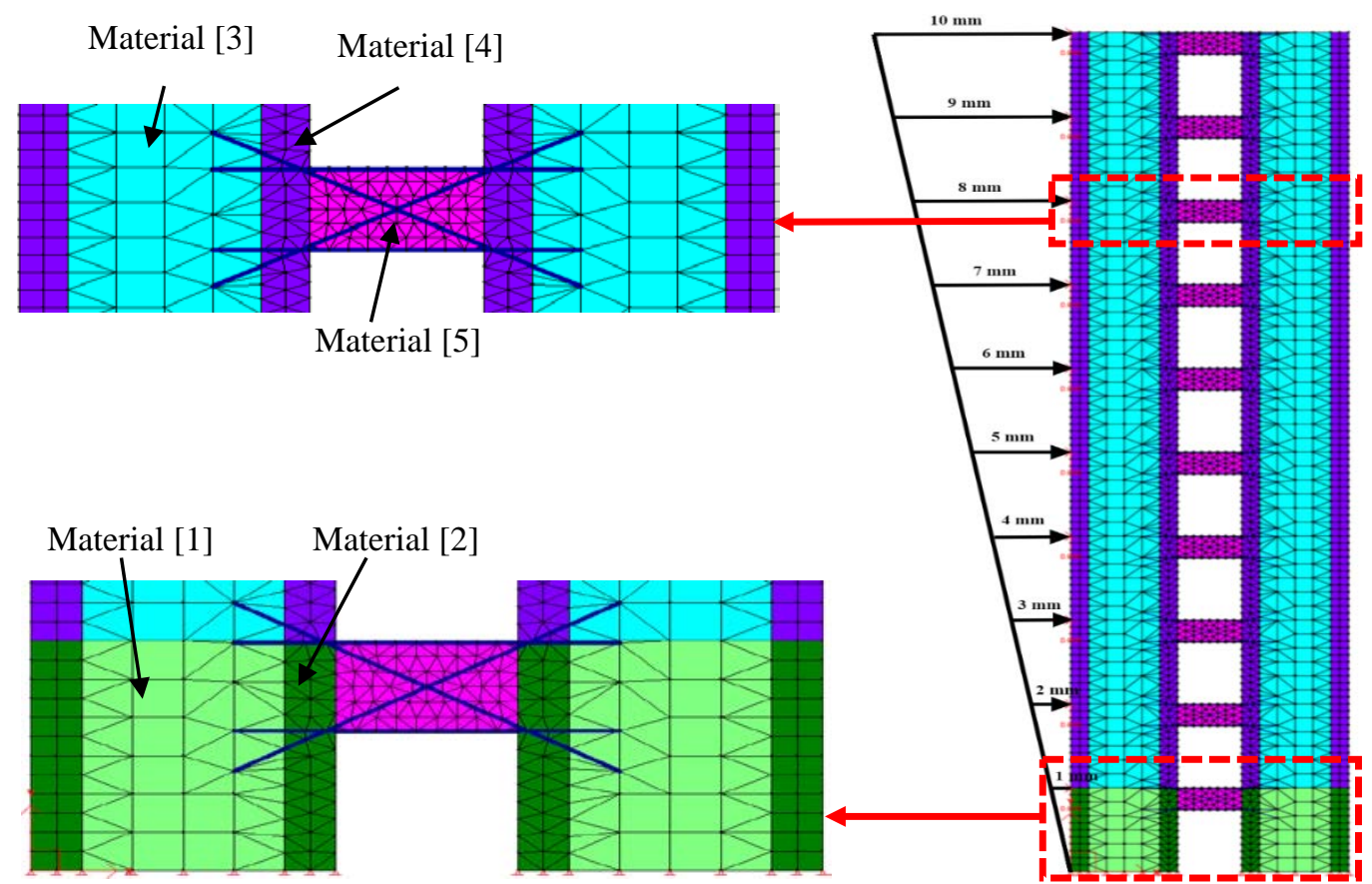

Figure 9. 2D Model of the CSW showing the pushover displacement, the diagonal reinforcement layout, and the different concrete material in different colors. 
Table 6. Concrete material properties used to model CSWs in VecTor2

\begin{tabular}{ccccccccccc}
\hline $\begin{array}{c}\text { Material } \\
\text { No. }\end{array}$ & $\begin{array}{c}\mathrm{f}^{\prime}{ }_{\mathrm{c}} \\
(\mathrm{MPa})\end{array}$ & $\begin{array}{c}\mathrm{f}^{\prime}{ }_{\mathrm{t}} \\
(\mathrm{MPa})\end{array}$ & $\begin{array}{c}\mathrm{E}_{\mathrm{c}} \\
(\mathrm{MPa})\end{array}$ & $\begin{array}{c}\gamma_{\mathrm{c}} \\
(\mathrm{kg} / \mathrm{m} 3)\end{array}$ & $\begin{array}{c}\mathrm{E}_{\mathrm{s}} \\
(\mathrm{MPa})\end{array}$ & $\begin{array}{c}\mathrm{F}_{\mathrm{y}} / \mathrm{F}_{\mathrm{u}} \\
(\mathrm{MPa})\end{array}$ & $\begin{array}{c}\rho_{\mathrm{v}} \\
(\%)\end{array}$ & $\begin{array}{c}\mathrm{D}_{\mathrm{v}} \\
(\mathrm{mm})\end{array}$ & $\begin{array}{c}\rho_{\mathrm{h}} \\
(\%)\end{array}$ & $\begin{array}{c}\mathrm{D}_{\mathrm{h}} \\
(\mathrm{mm})\end{array}$ \\
\hline 1 & 24 & 2.4 & 24100 & 2500 & 200000 & $400 / 600$ & 2 & 20 & 0.75 & 12 \\
2 & 24 & 2.4 & 24100 & 2500 & 200000 & $400 / 600$ & 7.9 & 25 & 1.13 & 12 \\
3 & 24 & 2.4 & 24100 & 2500 & 200000 & $400 / 600$ & 1.3 & 16 & 0.37 & 12 \\
4 & 24 & 2.4 & 24100 & 2500 & 200000 & $400 / 600$ & 6 & 22 & 0.75 & 12 \\
5 & 24 & 2.4 & 24100 & 2500 & 200000 & $280 / 360$ & 0.2 & 8 & - & - \\
\hline
\end{tabular}

\section{Results}

In this study, a quantitative examination into five different parameters and their effect on the CSWs system behavior was conducted. The summary of results is presented herein and readers interested in more detailed results are referred to [53].

\subsection{Effect of CB depth}

From the analysis, any increase in the CB span-to-depth ratio will be followed by an increase in the CSWs system shear and moment capacity. This increase had jumped after utilizing $1000 \mathrm{~mm}$ CB depth at a span-to-depth ratio of 1.8 as shown in Fig. 10. This jump could be interpreted as a point of change in the system stiffness due to the significant increase in the shear capacity of the CB. This value of span-to-depth ratio converted the ordinary beam to a deep beam which increased the CSWs system stiffness, and the shear capacity. Any further increase beyond $1000 \mathrm{~mm}$ for the CB depth at a span-to-depth ratio of 1.8 will not affect the lateral load resistance significantly, because the system stiffness is nearly constant, and the ultimate lateral load resistance is considered the same at CB models with a depth of 1000, 1100, and $1200 \mathrm{~mm}$.

The exhibited behavior could be interpreted by investigating the crack pattern and failure mechanism of the CSWs system. For CBs with a span-to-depth ratio of more than two, after the assigned loads exceed the wall yield capacity, flexure hair cracks (with size less than $0.5 \mathrm{~mm}$ ) start to propagate in the windward wall of the coupled wall system, which is subjected to tension. Those small cracks spread out in this wall, at the same time with flexure cracks at the beam-wall joint. The pattern of flexure cracks in the wall and CBs are as shown in Fig.11(a). The CB did not have enough depth to form a strut action. Therefore, it will provide a low level of coupling and it will behave like any ordinary flexure beam. Flexure cracks become wider after increasing the assigned loads more than the yielding load. The beams start to form plastic hinges at the beam-wall joint after suffering from additional flexure stresses, which lead to major cracks in the tension sides. On the other hand, the walls are still stiff enough to resist more loads without any major cracks. Reaching the ultimate load, the CB cracks get joined to each other and form a single vertical crack leading to a failure surface at the beam-wall joint. A complete plastic hinge will be formed, and the CBs start to fail one by one in a ductile failure mode (flexure failure). After losing many CBs, the walls start to carry the loads as separate weak cracked walls. Meanwhile, the wall minor cracks in the windward wall turned to be major cracks after exceeding the wall flexure capacity. The failure starts when the zone above the wall plastic hinge gets subjected to stresses more than the section capacity leading to major cracks. Those cracks decrease the wall flexure capacity and then the wall starts to fail.

For a span-to-depth ratio of less than two, after assigning the lateral load, flexure hair cracks will start to open in the CBs at the tension sides at the same time with wall flexure hair cracks. Then, two types of failure will compete to dominate the CB failure mode (flexure failure and shear tension failure), but the flexure cracks will not completely open until overcoming the compression diagonal strut. Therefore, diagonal cracks will start to open at the same time with flexure cracks. The CB flexure stiffness is enough to resist the applied flexure stresses. However, the compression diagonal strut will suffer excessive cracking due to exceeding the compression capacity as shown in Figure 11(b). Diagonal cracks will open after increasing the lateral load step by step to reach the ultimate capacity of the coupled wall system. The CBs will start to fail one by one due to the instability of the compression strut and finally, a shear tension failure will be dominated.

After testing five CB depths, the findings were that there is a nearly linear relationship between the CB depth and the CR as shown in Fig. 12. For CB depth of $800 \mathrm{~mm}$ at a span-to-depth ratio of 2.25, the CR was 56\%. Any further $100 \mathrm{~mm}$ increase in the CB depth will increase the CR by nearly 4\%. This could be interpreted by any increase in the $\mathrm{CB}$ depth will increase the capability of these beams to restrain more axial deformations. Therefore, the connected shear walls had to exert more effort to overcome the restrained axial deformation by the CBs, which means higher resisting to external lateral load. Finally, the CR will equal $72 \%$ at a span-to-depth ratio of 1.5 . However, increasing the CR up to $72 \%$ in the current case is not good from the ductile behavior perspective. Such a high level of coupling will lead to a wall failure before the failure of sufficient numbers of coupling beams which is not the intended failure mechanism. 


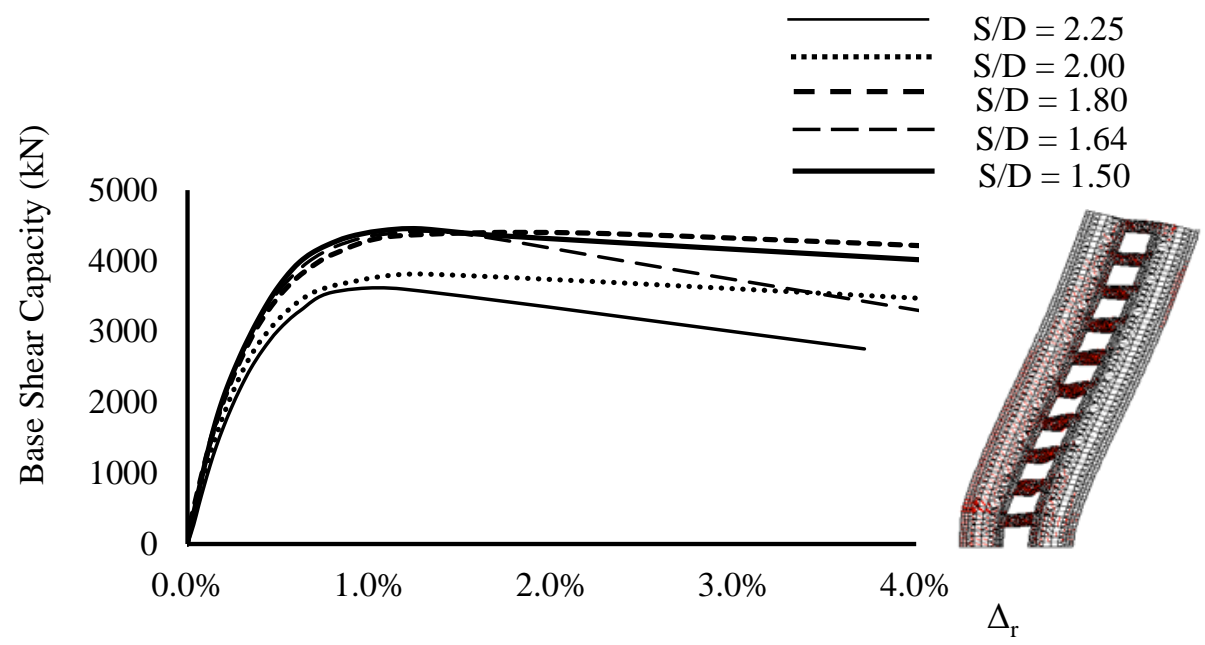

Figure 10. The effect of CB span-to-depth ratio (S/D) on the CSWs shear capacity.

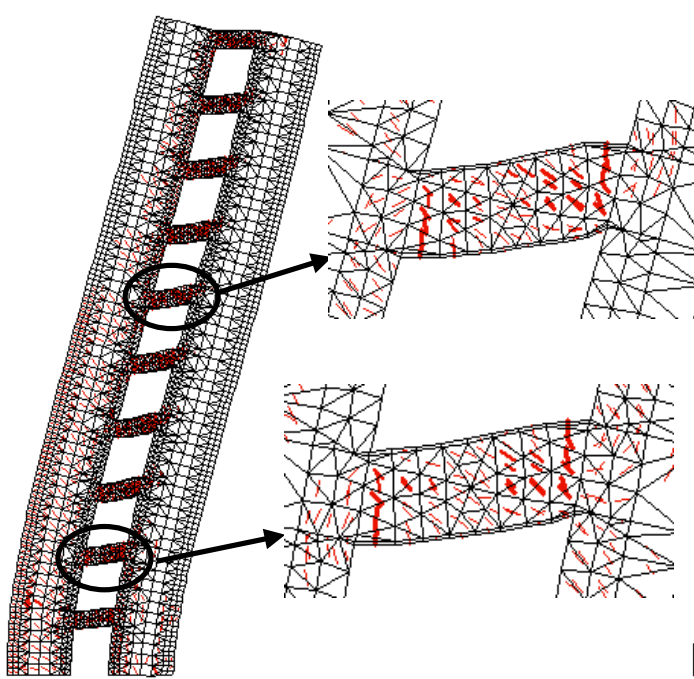

(a) $\mathrm{S} / \mathrm{D}=$

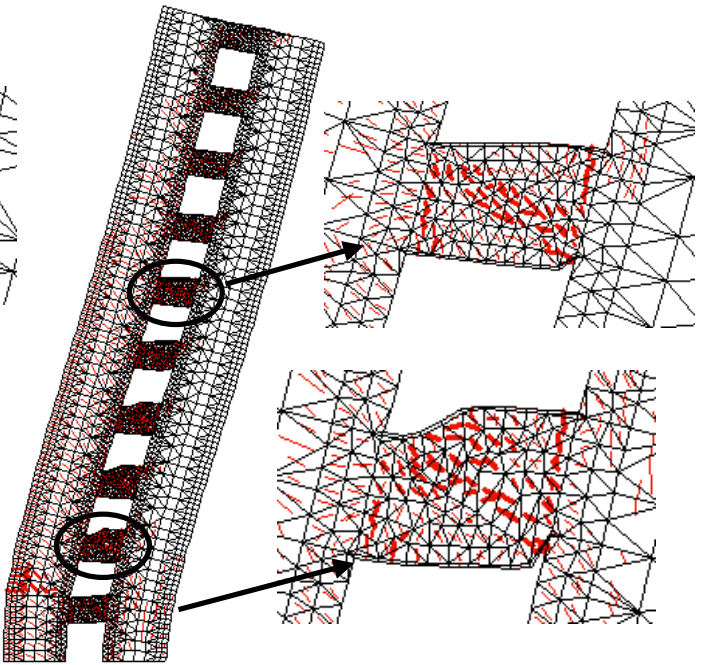

(b) $\mathrm{S} / \mathrm{D}=1.50$

Figure 11. The crack pattern of the CSWs system at the ultimate load: (a) S/D of the $C B=2.25$; (b) S/D of the $\mathrm{CB}=1$.

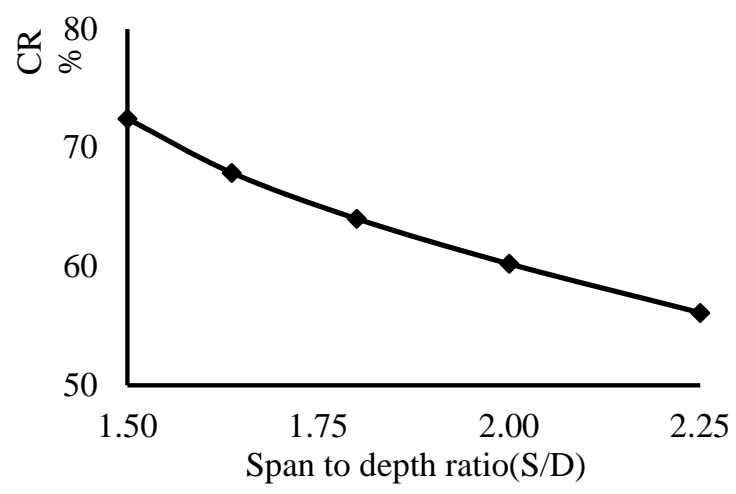

Figure 12. The effect of CB span-to-depth ratio on the CSWs system CR.

\subsection{Effect of CB width}

The shear resistance of the CSWs will slightly get increased with increasing the CB width. The CSWs system stiffness did not highly get affected by increasing the CB width as shown in Figure 13. A little increase in the CB 
width from $200 \mathrm{~mm}$ to $300 \mathrm{~mm}$ will make a 3.0\% increase in the lateral shear resistance, which is not considered a high percentage in comparison with a small increase in the CB depth. Theoretically, increasing the CBs width will increase the whole system stiffness; However, this stiffness increase is not as high as increasing the CB depth. Since, the major parameter that affects the CB participating stiffness is its depth, while the width is a less effective parameter. However, it is highly recommended for the best engineering practice to use CBs width equal to the width of the connected walls.

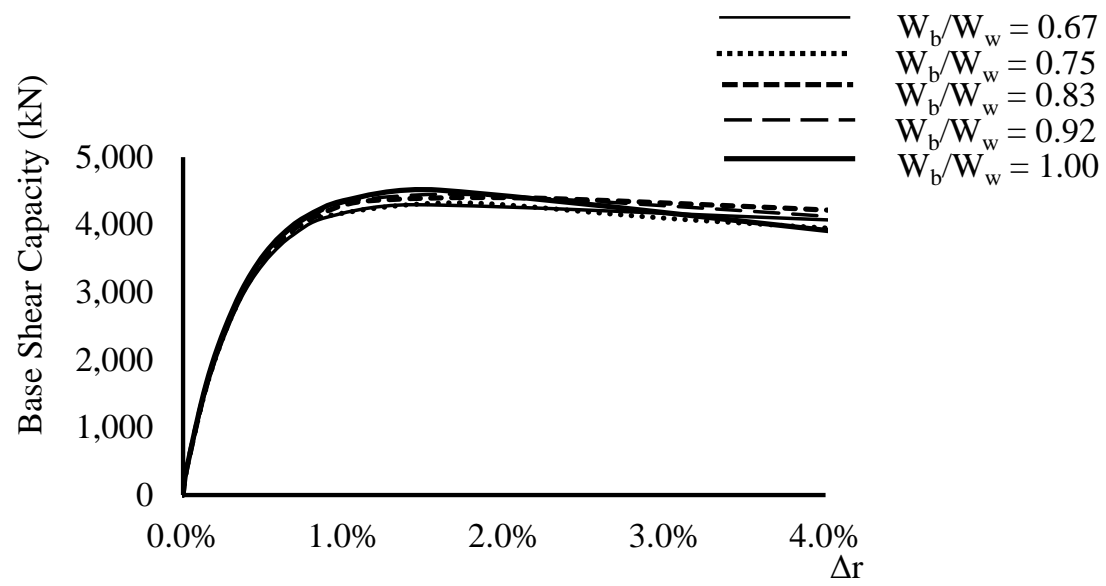

Figure 13. The effect of $\mathrm{CB}$ width ratio (width of the beam to the width of the wall $\mathrm{Wb} / \mathrm{Ww}$ ) on the CSWs capacity

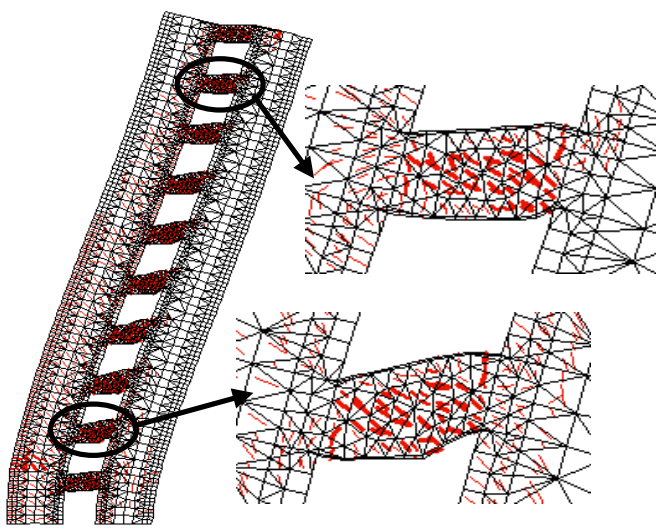

(a) $\mathrm{CB}$ width $=200$

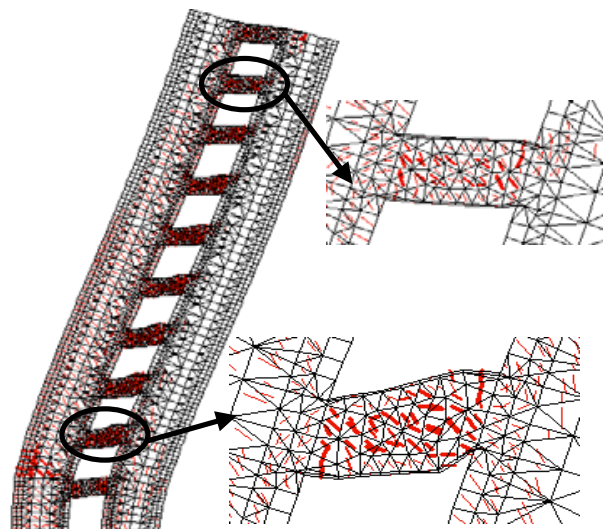

(b) $\mathrm{CB}$ width $=300 \mathrm{~mm}$

Figure 14. The crack pattern of the CSWs system at the ultimate load: (a) $\mathbf{C B}$ width $=\mathbf{2 0 0} \mathbf{~ m m}$; (b) $\mathbf{C B}$ width = $300 \mathrm{~mm}$

As discussed above, the CB width will have a little effect on the CB shear resistance. Therefore, the failure mechanism will not get affected by the increase of the CB width. As shown in Fig. 14, the coupled wall system fails in combined diagonal shear tension failure and flexure failure in most of the CBs. Therefore, the coupled wall systems with different $\mathrm{CB}$ widths exhibited almost the same performance and same lateral load resistance. Increasing CB width has a little effect on the coupled wall system behavior than increasing the CB depth. The overall increase of CR from CB width $200 \mathrm{~mm}$ up to $300 \mathrm{~mm}$ is $4.0 \%$ as shown in Fig. 15. This increase in CB width will not affect the failure mechanism of the CSWs system as discussed earlier. Therefore, it is better to choose CB width equals to the wall width. Such choice will give the highest CR and highest lateral load resistance in terms of shear and moment capacity of the coupled wall system in addition to following the best engineering practice.

\subsection{Effect of CB diagonal RFT}

Increasing the CB diagonal RFT will increase the beam shear resistance and make it stiffer to resist lateral loads and delay the CSWs system failure. As shown in Fig. 16, increasing the diagonal RFT ratio ( $\mu$ ) (the area steel of one group of diagonal bars divided by the area of the cross-section) from four bars of diameter $20 \mathrm{~mm}\left(1256 \mathrm{~mm}^{2}\right)$ at $\mu=0.5 \%$ (CB 4Ф20) to four bars of diameter $25 \mathrm{~mm}\left(1963 \mathrm{~mm}^{2}\right)$ at $\mu=0.8 \%(\mathrm{CB} 4 \Phi 25)$ will result in a great effect on the coupled wall system shear capacity. Any further increase in the area steel of diagonal RFT beyond $\mu=0.8 \%$ will have a lower effect on the moment and shear capacity of the CSWs system with minor changes in the 
system stiffness. After the coupled walls reach the yield load, cracks will propagate in the walls and the connecting CBs. From the load-roof drift history in Fig. 16, each coupled wall model has a different stiffness after the yield load. These different stiffnesses are due to the different plastic mechanisms, which were exhibited by each coupled wall model according to each different shear resistance of the CBs.

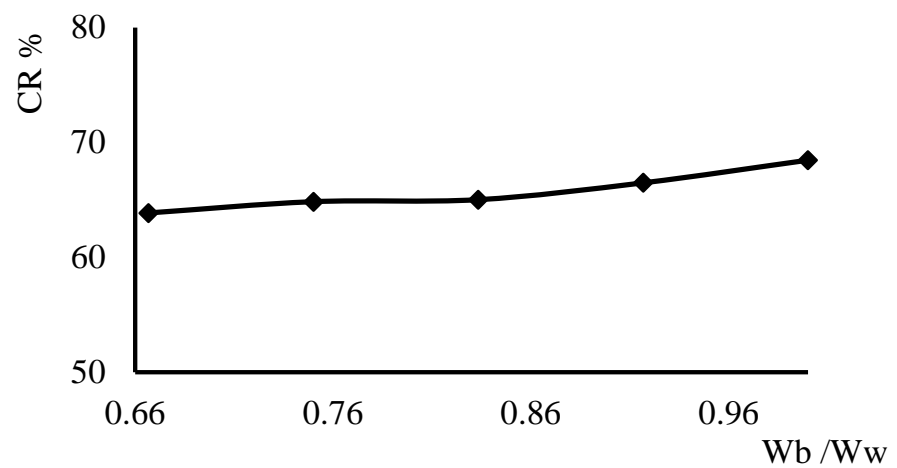

Figure 15. The effect of $\mathrm{CB}$ width ratio (width of the beam to the width of the wall) on the wall system CR

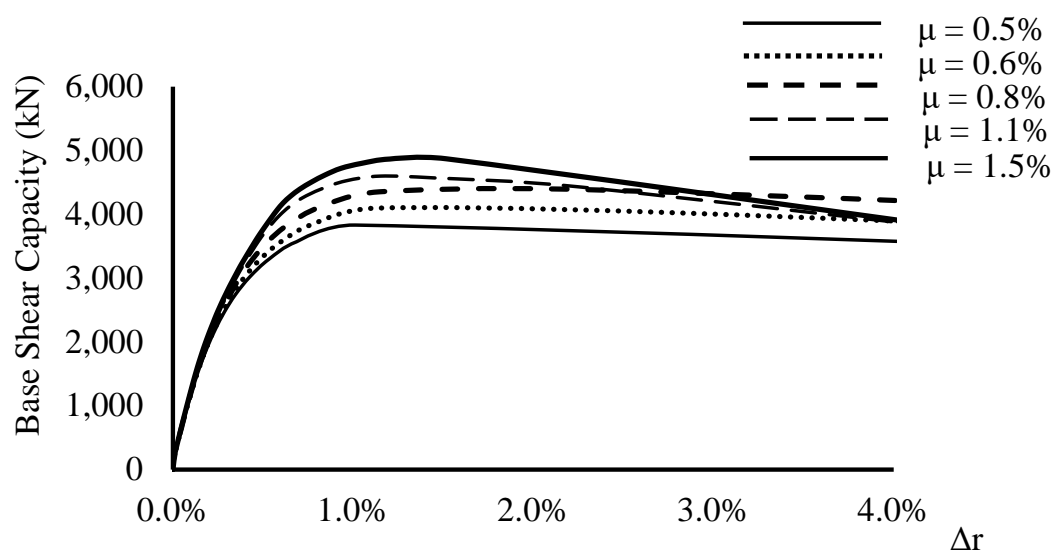

Figure 16. The effect of CB diagonal RFT ratio on the CSW shear capacity (using inverted triangle load).

For CB 4Ф20 up to CB 4Ф25, all the CBs failed before major failure in the connected walls, which means that walls are still strong and work with high efficiency in resisting the assigned lateral loads as shown in Fig. 17(a). However, if the diagonal RFT ratio exceeded $0.8 \%$, the CBs will suffer major cracks in the walls without failure of one-half of the connecting CBs, which mean that the main resisting elements lost a great portion of their stiffness in resisting the applied loads as shown in Fig. 17(b). The action of wall failure before the failure of most of the CBs is called over-coupling and this behavior should be avoided. Therefore, any further increase in the CB diagonal RFT will increase the coupled wall system capacity and failure load, but it will result in an undesired failure mechanism. So far, we could claim that the area steel of the CB diagonal RFT could change the coupled wall system response significantly. Increasing the CB area steel of diagonal RFT will increase the compression strut strength and the CB shear resistance which will make the CB exert more effort to overcome the strutting action. Consequently, the flexure cracks will not start to open without overcoming the strut action which will increase the capability of the beam to restrain more induced axial deformation in the walls. The coupled wall behavior changes significantly at different levels of diagonal RFT. If there is not sufficient diagonal area steel, low coupling action will be induced, and flexure failure will be dominated. If there is sufficient diagonal area steel, a medium coupling will be induced, and combined flexure and shear tension failure will be dominated as happened in the models reinforced with diagonal area steel up to 4Ф25 as shown in Figure 17(a). However, if the CB was diagonally reinforced with steel amount above $4 \Phi 25$, a higher level of coupling will be induced, and shear tension failure will be dominated which is the same case for diagonal RFT of 4Ф30 and 4Ф35 as shown in Fig. 17(b).

Using diagonal RFT of $4 \Phi 20$ provides CR of $59 \%$ and any further increase in the area steel of diagonal RFT will increase the CB shear resistance and enable the CBs to restrain more wall axial deformation until makes the CR reach its maximum value of 78\% at diagonal RFT 4Ф35. This high level of coupling is due to increasing the strength of the compression strut by increasing its RFT, which forces the wall to exert more effort to overcome the restrained axial deformation by CBs. Hence, any increase in the CB area steel of diagonal RFT, which means a strong compression strut and a high level of coupling. This increase in the CR will be reflected on the failure 
mechanism as shown in Fig. 17. As shown in Fig. 18, there is a nearly linear relationship between increasing the CB area steel of diagonal RFT and the CR and this will be reflected in the system capacity to resist lateral loads. Although a high level of coupling at $78 \%$ when using diagonal RFT of $4 \Phi 35$ will increase the overall system capacity to resist lateral load, it will not provide the desired failure mechanism as we discussed before for the overcoupled CSWs.

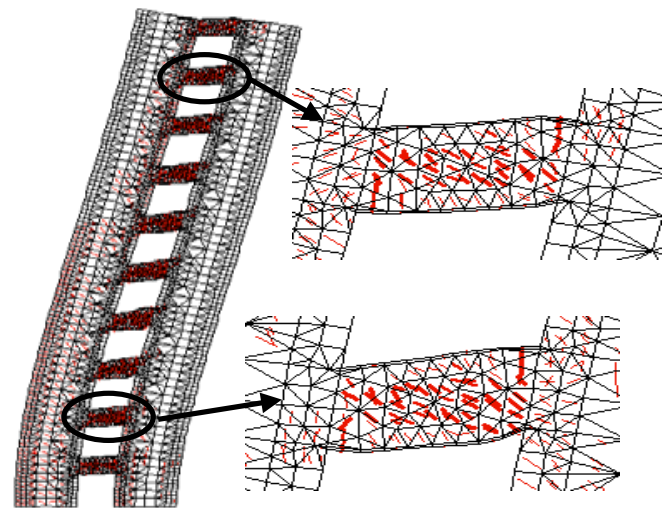

(a) Diagonal RFT $=4 \Phi 20$

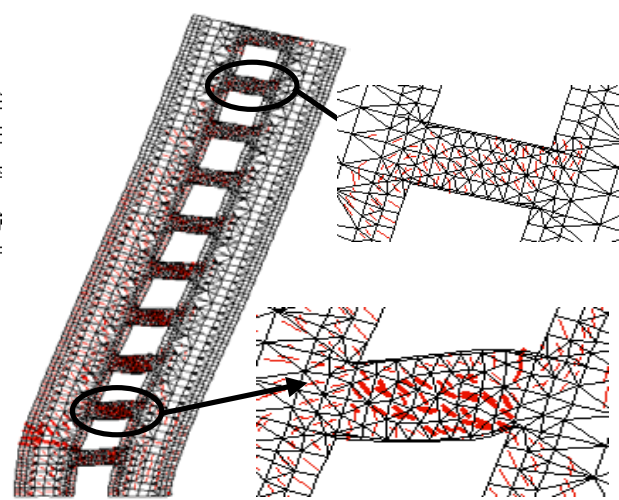

(b) Diagonal RFT $=4 \Phi 35$

Figure 17. The crack pattern of the coupled wall system at the ultimate load: (a) Diagonal RFT = 4Ф20; (b) Diagonal RFT $=4 \Phi 35$.

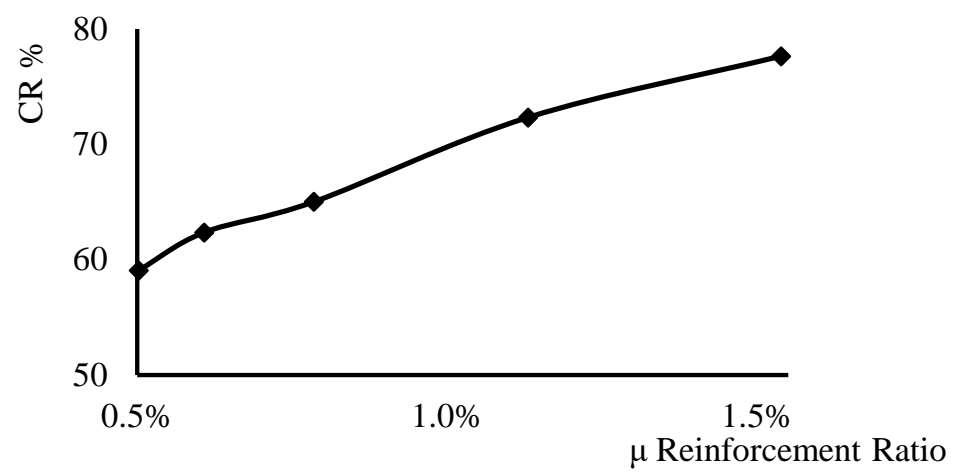

Figure 18. The effect of CB diagonal RFT ratio on the wall system CR.

\subsection{Effect of CB longitudinal RFT}

Increasing the CB top and bottom RFT will not highly affect the CSWs system stiffness as shown in Fig. 19. However, the load-roof drift history of the coupled wall system after the yield load has a different stiffness. These different stiffnesses after the yield load are due to the different plastic mechanisms, which had been exhibited by each coupled wall model according to each different flexure resistance of CBs. So, increasing the CB area steel of flexure top and bottom RFT will result in a little increase in the ultimate shear resistance of the CSWs. Also, attention should be given to the failure mechanism induced due to the increase of the flexure top and bottom RFT. Since, after the flexure RFT ratio (the area steel of the top or the bottom bars divided by the area of the crosssection) exceeds $0.24 \%$, the CB flexure strength will be high enough to change the coupled wall failure mode from combined flexure and diagonal shear tension failure to a pure brittle shear tension failure. So, a maximum limit on the CB flexure top and bottom RFT of $0.24 \%$ should be provided to avoid a brittle pure diagonal shear tension failure. To that end, if there is a high amount of flexure RFT, the CB flexure strength will be increased enough to change the failure mode of the CB from combined flexure and shear tension failure to a pure brittle shear tension failure and this explains the pure brittle shear tension failure at longitudinal RFT ratio of $0.59 \%$ as shown in Fig. 20. Although increasing the CB area of flexure top and bottom RFT will not affect the model stiffness greatly, it will increase the flexure resistance of the CB. Such an increase in flexure strength of the CB will not affect the wall's axial deformation. Therefore, there is no relationship between increasing the CB flexure RFT and the CR as shown in Fig. 21. 


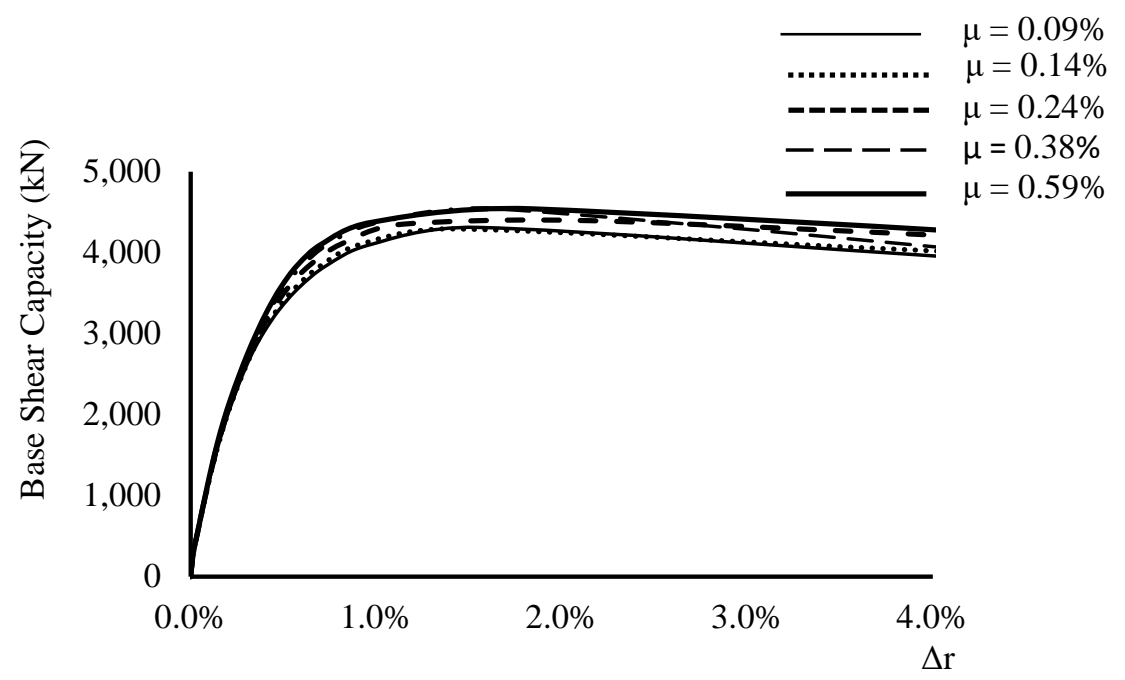

Figure 19. The effect of CB flexure RFT ratio $(\mu)$ on the CSWs system capacity (Inverted Triangle load)

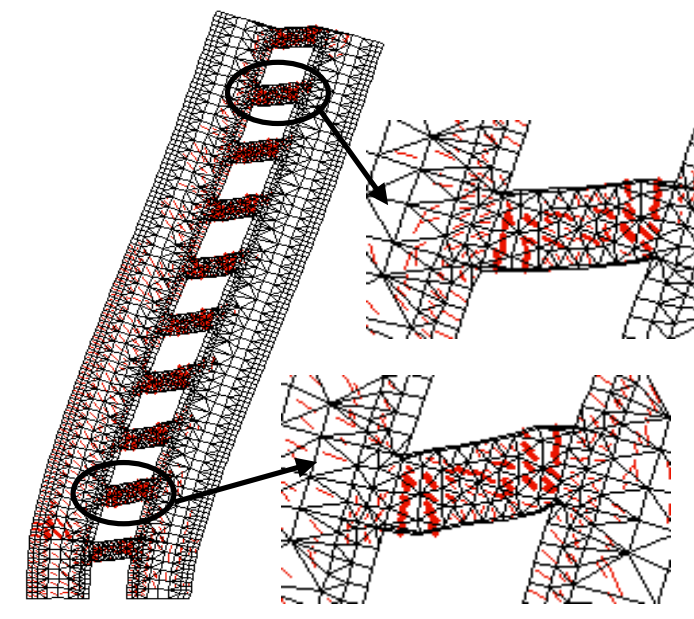

(a) $\mathrm{CB}$ Flex. RFT $=3 \Phi 10$

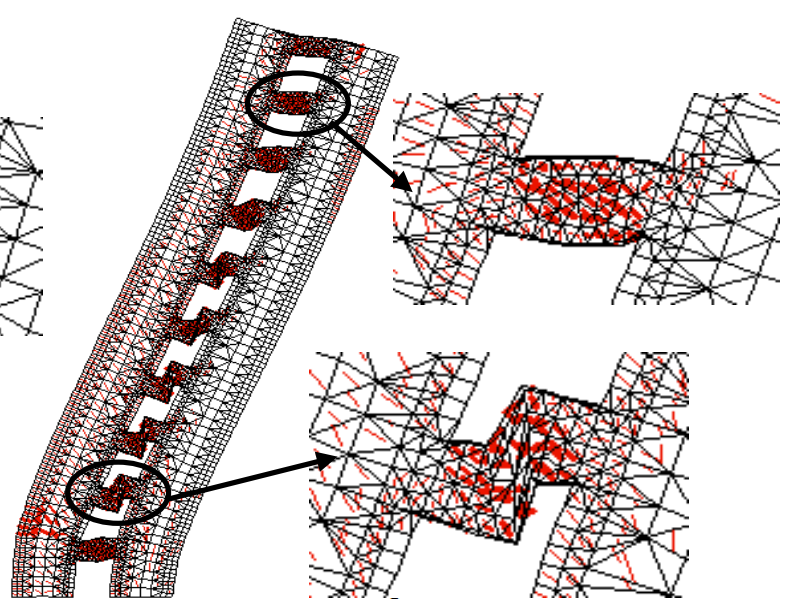

(b) CB Flex. RFT $=3 \Phi 25$

Figure 20. The crack pattern of the coupled wall system at the ultimate load: (a) CB Flex. RFT= 3Ф10; (b) CB Flex. RFT = 3Ф25

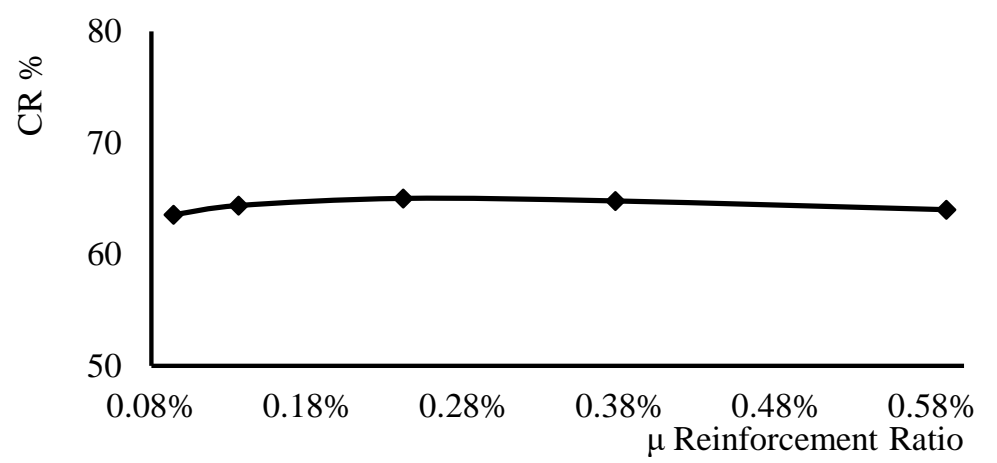

Figure 21. The effect of CB flexure reinforcement ratio $(\mu)$ on the wall system CR

\subsection{Effect of CB shear stirrups RFT}

Any increase in the CB shear RFT stirrups will have a slight effect on the coupled wall resistance in terms of lateral shear resistance as shown in Fig. 22. Increasing the shear RFT stirrups from $4 \Phi 8 / \mathrm{m}^{\prime}$ at $\mu=0.16 \%$ up to $12 \Phi 8 / \mathrm{m}^{\prime}$ at $\mu=0.48 \%$ will have a little increase of $3.7 \%$ in the system moment capacity and $2.0 \%$ increase in the shear capacity. On the other hand, increasing the shear RFT stirrups could change the failure mechanism of the CSW dramatically. To that end, the different shear RFT stirrups exhibited almost the same shear capacity of the 
CSWs system. However, CBs with an amount of shear RFT stirrups that exceeds $\mu=0.25 \%$ will suppress the shear tension failure mode and enforced a shear sliding failure mechanism at the beam-wall joint of the CBs as shown in Figure 23(b). So, attention should be given to the minimum and maximum level of shear RFT ratios to avoid undesirable behavior. As shown in Fig. 24, the CR at shear stirrups RFT ratio $\mu=0.16 \%$ is $65 \%$ while increasing the shear RFT ratio to reach $\mu=0.48 \%$ will result in a $2.0 \%$ increase in the CR to be $67 \%$. This $2.0 \%$ increase in the CR resulted from the suppressed shear tension failure and preventing the compression strut from the early failure by the additional confinement which has a minor effect on the CR. Table 7 summarizes the study results in terms of the CSWs base shear capacity and CR for each parametric model. Additionally, Fig. 25 shows all the results on the same plot with the x-axis represent the parametric model for the 25 tested models. Parametric Model (3) which is in red is a common model parameter for each tested property which describes why all the curves intersect at parametric model 3.

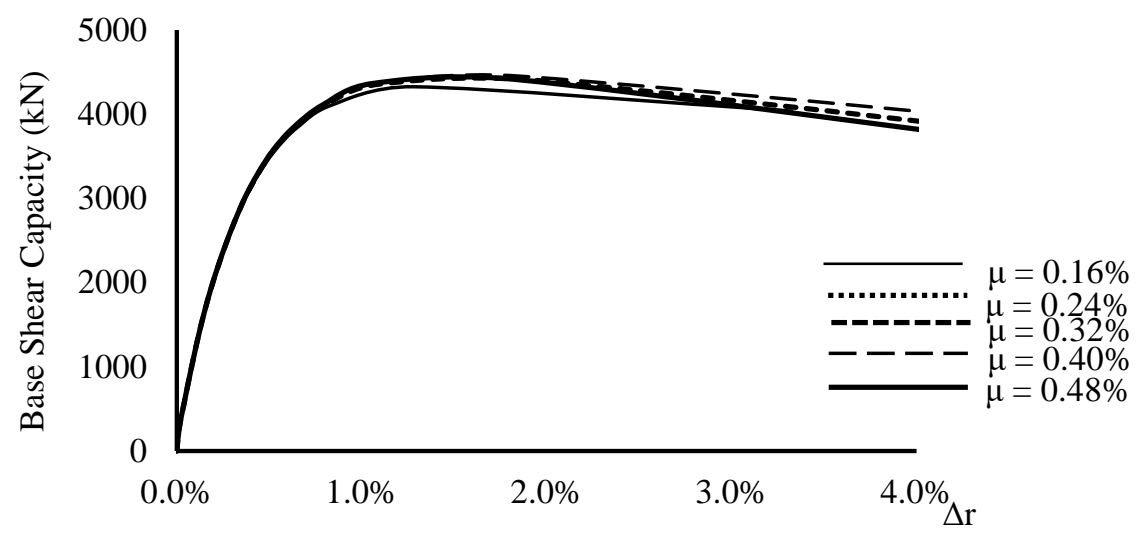

Figure 22. The effect of CB shear RFT ratio on the CSWs system capacity

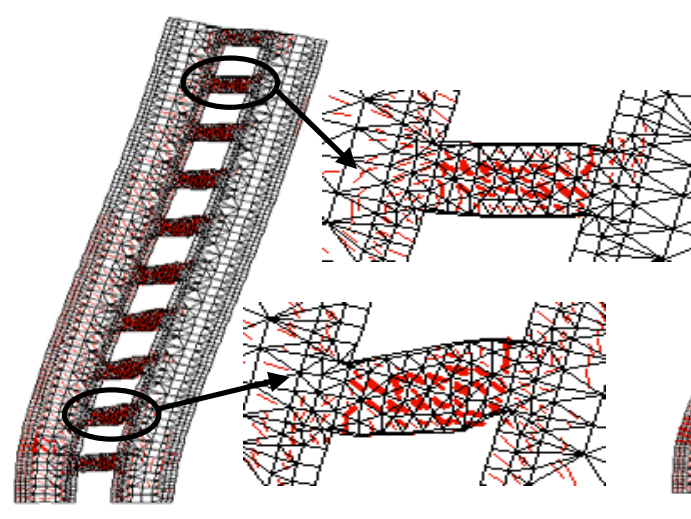

(a) CB Shear RFT $=4 \Phi 8 / \mathrm{m}$

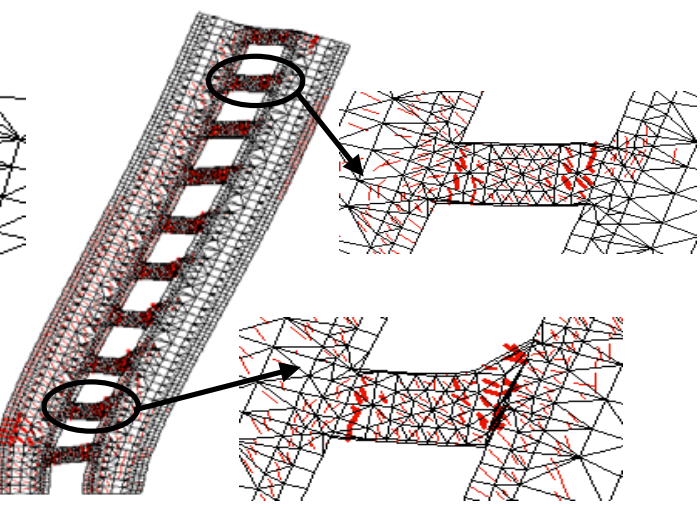

(b) CB Shear RFT $=12 \Phi 8 / \mathrm{m}$ '

Figure 23. The crack pattern of the CSWs system at the ultimate load: (a) CB Shear RFT = 4Ф8/m'; (b) CB Shear RFT $=12 \Phi 8 / \mathrm{m}$,

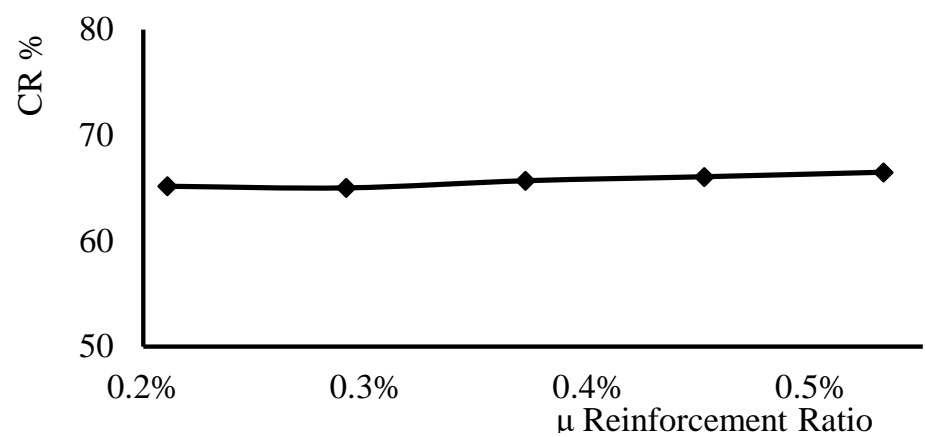

Figure 24. The effect of CB shear reinforcement ratio on the CSWs system CR 
Table 7. Results summary in terms of the CSWs base shear capacity and CR

\begin{tabular}{ccccccccccc}
\hline \multirow{2}{*}{$\begin{array}{c}\text { Parametric } \\
\text { Model }\end{array}$} & \multicolumn{2}{c}{ Depth } & \multicolumn{2}{c}{ Width } & \multicolumn{2}{c}{ Diagonal RFT } & \multicolumn{2}{c}{ Flexure RFT } & \multicolumn{2}{c}{ Shear RFT } \\
\cline { 2 - 10 } & Vu & CR & Vu & CR & Vu & CR & Vu & CR & Vu & CR \\
\hline 1 & 3602 & 56 & 4296 & 64 & 3832 & 59 & 4313 & 64 & 4326 & 65 \\
2 & 3815 & 60 & 4324 & 65 & 4096 & 62 & 4346 & 64 & 4386 & 65 \\
$3^{*}$ & 4386 & 65 & 4386 & 65 & 4386 & 65 & 4386 & 65 & 4395 & 65 \\
4 & 4394 & 68 & 4440 & 66 & 4599 & 72 & 4534 & 65 & 4451 & 67 \\
s & 4454 & 72 & 4511 & 68 & 4871 & 78 & 4541 & 64 & 4414 & 67 \\
\hline
\end{tabular}

*The base coupling beam parameters are $1000 \mathrm{~mm}$ depth, $250 \mathrm{~mm}$ width, 4T25 diagonal RFT, 3T16 top and bottom RFT, and $8 \mathrm{Y} 8$ shear stirrups RFT. The units for $\mathrm{V}_{\mathrm{u}}$ are $\mathrm{kN}$ and the unit for CR is \%.

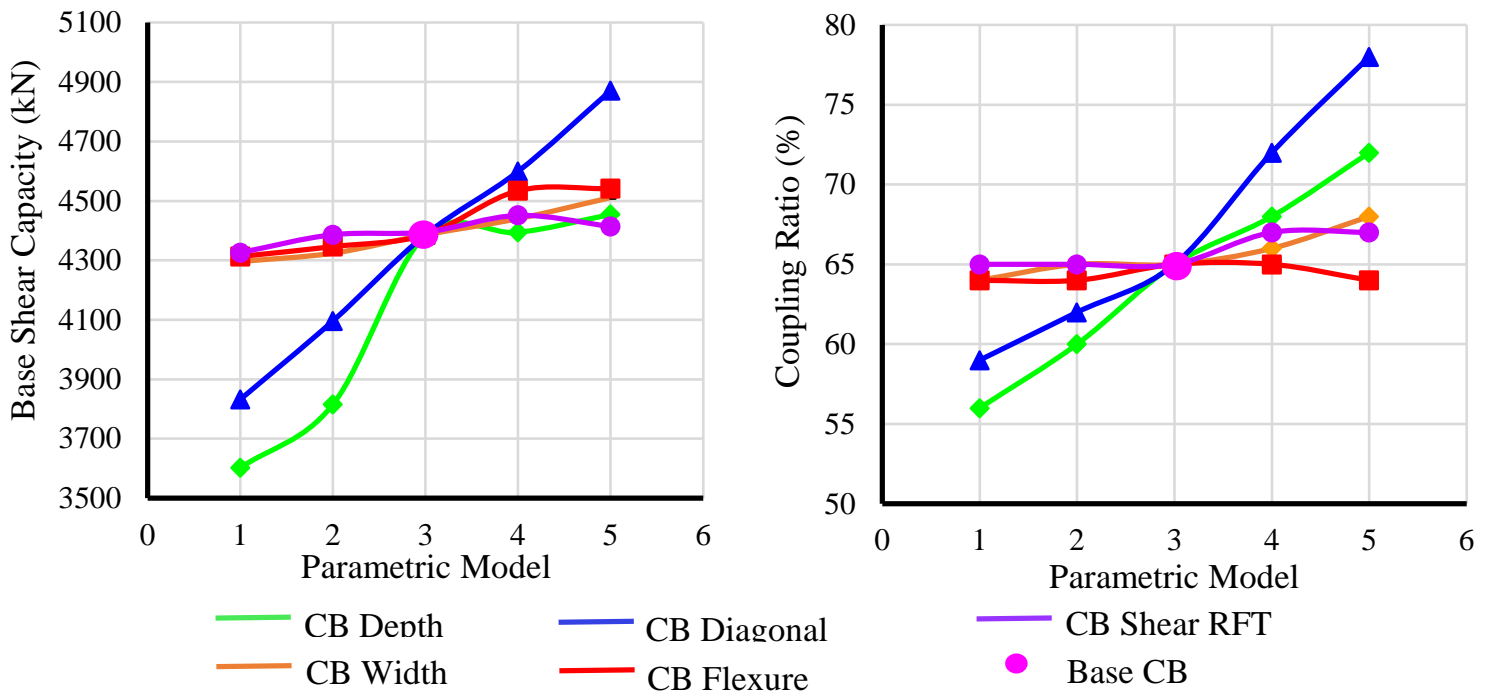

Figure 25. Results summary in terms of the CSWs base shear capacity and CR

\section{Summary and conclusions}

In this study, the coupled shear walls behavior was studied using finite element analysis along with the direct application of the MCFT. The adopted finite element and material models were verified using previous experimentally tested CBs. The verification showed an excellent match between the numerical and experimental results in terms of the induced forces and the captured crack pattern. Following verifications, a full-scale 10-story CSWs finite element model was developed to investigate the effect of the CB parameters on the whole response of CSWs system. A nonlinear static pushover analysis method was used to quantify the effect of CB parameters (depth, width, diagonal RFT, top and bottom RFT, and shear RFT stirrups) on the overall behavior of the CSWs system. The following are observations about the effect of the CB strength on the CSWs behavior:

1) CB span-to-depth ratio has a substantial effect on the CB strength. A span-to-depth ratio of two was found to be a transition point of the CB behavior. If the CB span-to-depth ratio was more than two, the CB behavior was similar to the behavior of an ordinary flexural beam with a low level of coupling to the shear walls. However, if the ratio was less than two, the behavior conformed to that of a deep beam because of the formation of a diagonal strut which in turn forces the CB to exert more effort to overcome this strut action. So, it is recommended to use CBs with a span-to-depth ratio between 2 to 1.8, thereby optimizing the overall performance of the CSWs and achieving the failure mechanism at extreme loads.

2) Any increase in the CB depth will increase the system capacity. However, span-to-depth ratio of two is considered optimal for CBs because it enables the CSWs system to maintain a higher level of ductility, high lateral load resistance in terms of shear and moment capacity, and a medium level of coupling. Therefore, a medium coupling will enable the wall to maintain the highest performance because the low level of coupling decreases the strength of the wall to lateral loads, and high coupling reduces the system ductility.

3) CB depth should not be very shallow (span to depth ratio more than 4) and not enough to provide any coupling, which makes CBs fail early. Besides, it should not be so deep enough to make CBs very stiff, which makes the coupled wall system over coupled with less ductile failure mode. Thus, the wall will fail first before the failure of a sufficient number of CBs.

4) CR is significantly affected by the span-to-depth ratio of the CB. Any small increase in the CB depth, which means less span-to-depth ratio will be accompanied by a nearly linear increase in the CR. This increase will be 
reflected in the whole system failure mechanism.

5) The diagonal RFT pattern is a necessity, if the CB span-to-depth ratio is less than two, to avoid diagonal shear tension failure. On the other hand, if the span-to-depth ratio is more than two, flexure failure mode will be dominant and a conventional RFT could be used rather than the diagonal RFT.

6) The area steel of CB diagonal RFT could change the coupled wall system response significantly. Any increase in the CB diagonal RFT will increase the system performance in terms of shear and moment capacity. However, attention should be given to how this amount of RFT is going to affect the failure mechanism and check if this mechanism is acceptable or unacceptable.

7) A nearly linear relationship between increasing the CB area steel of diagonal RFT and the CR and was observed. The coupling level should be accurately selected to enable the desired failure mechanism.

8) Limitations on diagonal RFT should be provided to avoid undesired failure mechanisms. If the diagonal RFT ratio of the $\mathrm{CB}$ is $0.8 \%$ for this case study, the coupled wall system was in a medium coupling, and the walls showed an excellent behavior in terms of energy dissipation, wall rotation, inter-story drifts, and failure mechanism.

9) Increasing the CB width, longitudinal, and shear stirrups RFT will not affect the behavior of the CSWs significantly in terms of shear and moment capacity. It could be said, if these parameters got increased, the system capacity will increase but at a slower rate than CB depth and diagonal RFT increase. However, it is highly recommended to use CBs with equal width to that of the connected walls, and the shear RFT stirrups ratio does not exceed $0.24 \%$. This will enhance the overall performance of the CSWs.

10) An upper limit of $0.24 \%$ of the shear RFT stirrups ratio and flexure RFT ratio should be provided to ensure the intended failure mechanism. The most desired failure mechanism concluded by this research is a ductile diagonal shear tension failure mode at the same time with a flexure failure in the walls. Therefore, if there is a high ratio of shear stirrups RFT, the diagonal tension failure of the CB could be suppressed and shear sliding failure at the beam-wall joint could be dominated. Additionally, if the flexure RFT ratio exceeded $0.24 \%$, the CB flexure strength will be high enough to change the coupled wall failure mode from combined flexure and diagonal shear tension failure to a pure brittle shear tension failure. Finally, either increasing the CB confinement or the flexure RFT will not affect the CR and could be neglected, but it substantially affects the CSWs failure mechanism.

\section{Acknowledgment}

The authors acknowledge two professors from the Department of Civil and Environmental Engineering at Colorado State University: Prof. John van de Lindt and Prof. Hussam Mahmoud. They assisted in editing and reviewing the manuscript.

\section{References}

[1] Paulay T. Coupling beams of reinforced concrete shear walls. Journal of the Structural Division. 1971;97(3):843-862.

[2] El-Tawil S, Kuenzli CM, Hassan M. Pushover of hybrid coupled walls. I: Design and modeling. Journal of Structural Engineering. 2002;128(10):1272-1281.

[3] Harries KA, Fortney PJ, Shahrooz BM, Brienen PJ. Practical design of diagonally reinforced concrete coupling beams-critical review of ACI 318 requirements. ACI Structural Journal. 2005;102(6):876.

[4] Harries KA, Gong B, Shahrooz BM. Behavior and design of reinforced concrete, steel, and steel-concrete coupling beams. Earthquake Spectra. 2000;16(4):775-799.

[5] Paulay T, Santhakumar AR. Ductile behavior of coupled shear walls. Journal of the Structural Division. 1976;102(1):93-108.

[6] Wallace JW. Behavior, design, and modeling of structural walls and coupling beams-Lessons from recent laboratory tests and earthquakes. International Journal of Concrete Structures and Materials. 2012;6(1):3-18.

[7] Harries KA, Moulton JD, Clemson RL. Parametric study of coupled wall behavior-implications for the design of coupling beams. Journal of Structural Engineering. 2004;130(3):480-488.

[8] Galano L, Vignoli A. Seismic behavior of short coupling beams with different reinforcement layouts. Structural Journal. 2000;97(6):876-885.

[9] Su RKL, Zhu Y. Experimental and numerical studies of external steel plate strengthened reinforced concrete coupling beams. Engineering structures. 2005;27(10):1537-1550.

[10] Zhao ZZ, Kwan AKH. Nonlinear behavior of deep reinforced concrete coupling beams. Structural Engineering and Mechanics. 2003;15(2):181-198.

[11] Lehman DE, Turgeon JA, Birely AC, Hart CR, Marley KP, Kuchma DA, et al. Seismic behavior of a modern concrete coupled wall. Journal of Structural Engineering. 2013;139(8):1371-1381.

[12] Cai G, Zhao J, Degée H, Vandoren B. Shear capacity of steel fibre reinforced concrete coupling beams using 
conventional reinforcements. Engineering Structures. 2016;128:428-440.

[13] Kwan AKH, Zhao ZZ. Testing of coupling beams with equal end rotations maintained and local joint deformation allowed. Proceedings of the Institution of Civil Engineers: Structures and Buildings. 2002.

[14] Zhao ZZ, Kwan AKH, He XG. Nonlinear finite element analysis of deep reinforced concrete coupling beams. Engineering Structures. 2004;26(1):13-25.

[15] He XG, Kwan AKH. Modeling dowel action of reinforcement bars for finite element analysis of concrete structures. Computers \& Structures. 2001;79(6):595-604.

[16] Harries KA. Ductility and deformability of coupling beams in reinforced concrete coupled walls. Earthquake Spectra. 2001;17(3):457-478.

[17] Park J, Strepelias E, Stathas N, Kwon O, Bousias S. Application of hybrid simulation method for seismic performance evaluation of RC coupling beams subjected to realistic boundary condition. Earthquake Engineering \& Structural Dynamics. 2021;50(2):375-393.

[18] El-Tawil S, Kuenzli CM. Pushover of hybrid coupled walls . II : Analysis and Behavior. 2002;128(10):12821289.

[19] Wang Z, Pan W. A hybrid coupled wall system with replaceable steel coupling beams for high-rise modular buildings. Journal of Building Engineering. 2020;31:101355.

[20] Harries KA, David S. McNeice. Performance-based design of high-rise coupled wall systems. The Structural Design of Tall and Special Buildings. 2006;15(3):289-306.

[21] Dahal P, Powell T, Mullen C. Hazard-independent stability sensitivity study of steel and RC frame structures. Journal of Civil Engineering and Construction. 2019;8(2):63-69.

[22] Choi Y, Hajyalikhani P, Chao S-H. Seismic performance of innovative reinforced concrete coupling beamdouble-beam coupling beam. ACI Structural Journal. 2018;115(1):113-125.

[23] Borello DJ, Fahnestock LA. Large-scale cyclic testing of steel-plate shear walls with coupling. Journal of Structural Engineering. 2017;143(10):4017133.

[24] Glück J. Elasto-plastic analysis of coupled shear walls. Journal of the structural Division. 1973;99(8):17431760.

[25] Paulay T. An Elasto-Plastic Analysis of Coupled Shear Walls. In: Journal Proceedings. 1970. p. 915-922.

[26] Pekau OA, Gocevski V. Elasto-plastic analysis of coupled shear walls. Engineering Structures. 1981;3(2):8795.

[27] Nabilah AB, Koh CG, Safiee NA, Mohd. Nasir NA. Analysis of conventionally reinforced coupling beams using non-linear strut-and-tie model. Proceedings of the Institution of Civil Engineers-Structures and Buildings. 2020;173(6):429-439.

[28] Kwan AKH, Zhao ZZ. Reinforced concrete coupling beams: their differences from ordinary beams. In: EPMESC VII. Elsevier; 1999. p. 581-588.

[29] Kwan AKH. Local deformations and rotational degrees of freedom at beam-wall joints. Computers \& Structures. 1993;48(4):615-625.

[30] Nayar KK, Coull A. Elastoplastic analysis of coupled shear walls. Journal of the structural Division. 1976;102(9):1845-1860.

[31] Ping C, Sheliang W. Method of wide-columns used for elasto-plastic analysis of coupled shear walls. Journal of Xi'an University of Architecture \&Technology. 1995;3.

[32] Harries KA, Mitchell D, Redwood RG, Cook WD. Nonlinear seismic response predictions of walls coupled with steel and concrete beams. Canadian Journal of Civil Engineering. 1998;25(5):803-818.

[33] Pala S, Özmen G. Effective stiffness of coupling beams in structural walls. Computers \& Structures. 1995;54(5):925-931.

[34] Kwan AKH, Chan WT. Non-planar beam-wall joints in tall building structures. Proceedings of the Institution of Civil Engineers: Structures and Buildings. 2000.

[35] Amar G. Analysis of reinforced concrete coupled shear wall using finite element method. Int J Educ Appl Res. 2014;33:24-30.

[36] Kwan AKH, Ng PL. Modelling dowel action of discrete reinforcing bars for finite element analysis of concrete structures. Computers and Concrete. 2013;12(1):19-36.

[37] Kwan AKH, He XG. Finite element analysis of effect of concrete confinement on behavior of shear walls. Computers \& Structures. 2001;79(19):1799-1810.

[38] Ding R, Tao M-X, Nie X, Mo YL. Analytical model for seismic simulation of reinforced concrete coupled shear walls. Engineering Structures. 2018;168:819-837.

[39] Nabilah AB, Koh CG, Izian AK, Aziz FNAA. Development of finite element analysis for intermediate length coupling beams considering bond-slip interface. International Journal of Concrete Structures and Materials. 2020;14(1):1-10.

[40] Wong PS, Vecchio FJ, Trommels H. Vector2 and Formworks User's Manual Second Edition. Toronto: Univ. of Toronto: Citeseer; 2013. 
[41] Vecchio FJ. Disturbed stress field model for reinforced concrete: formulation. Journal of Structural Engineering. 2000;126(9):1070-1077.

[42] Vecchio FJ, Collins MP. The modified compression-field theory for reinforced concrete elements subjected to shear. ACI J. 1986;83(2):219-231.

[43] Constantin R-T. Seismic behaviour and analysis of U-shaped RC walls. 2016.

[44] Hoult R, Goldsworthy H, Lumantarna E. Plastic hinge length for lightly reinforced rectangular concrete walls. Journal of Earthquake Engineering. 2018;22(8):1447-1478.

[45] Hognestad E. Study of combined bending and axial load in reinforced concrete members. University of Illinois at Urbana Champaign, College of Engineering. 1951.

[46] Kent DC, Park R. Flexural members with confined concrete. Journal of the Structural Division. 1971.

[47] Park R, Priestley MJ, Gill WD. Ductility of square-confined concrete columns. Journal of the structural Division. 1982;108(4):929-950.

[48] Bentz EC. Sectional analysis of reinforced concrete members. University of Toronto Toronto; 2000.

[49] Kupfer H, Hilsdorf HK, Rusch H. Behavior of concrete under biaxial stresses. In: Journal proceedings. 1969. p. 656-666.

[50] Kupfer HB, Gerstle KH. Behavior of concrete under biaxial stresses. Journal of the Engineering Mechanics Division. 1973;99(4):853-866.

[51] Richart FE, Brandtzaeg A, Brown RL. A study of the failure of concrete under combined compressive stresses. University of Illinois at Urbana Champaign, College of Engineering. 1928.

[52] Tassios TP, Yannopoulos PJ. Analytical studies on reinforced concrete members under cyclic loading based on bond stress-slip relationships. In: Journal Proceedings. 1981. p. 206-216.

[53] Nofal OM. Effect of non-linear behaviour of RC Coupling beams on the seismic response of the coupled shear walls system. Cairo University; 2017.

[54] ACI. Building code requirements for reinforced concrete. ACI 318-14. 2014.

[55] Portland Cement Association (PCA) for the engineering design and analysis of reinforced concrete. spWall. 2012.

(C) 2021 by the author(s). This work is licensed under a Creative Commons Attribution 4.0 International License (http://creativecommons.org/licenses/by/4.0/). Authors retain copyright of their work, with first publication rights granted to Tech Reviews Ltd. 